\title{
Drug-Resistant Fungi: An Emerging Challenge Threatening Our Limited Antifungal Armamentarium
}

\author{
Amir Arastehfar ${ }^{1}$, Toni Gabaldón $2,3,4 \oplus$, Rocio Garcia-Rubio ${ }^{1}\left(\mathbb{D}\right.$, Jeffrey D. Jenks ${ }^{5,6,7}$, \\ Martin Hoenigl 6,7,8 (D, Helmut J. F. Salzer ${ }^{9}$, Macit Ilkit 10,* , Cornelia Lass-Flörl ${ }^{11}$ \\ and David S. Perlin 1,* \\ 1 Center for Discovery and Innovation, Hackensack Meridian Health, Nutley, NJ 07110, USA; \\ amir.arastehfar@hmh-cdi.org (A.A.); Rocio.GarciaRubio@hmh-cdi.org (R.G.-R.) \\ 2 Life Sciences Programme, Supercomputing Center (BSC-CNS), Jordi Girona, 08034 Barcelona, Spain; \\ toni.gabaldon@bsc.es \\ 3 Mechanisms of Disease Programme, Institute for Research in Biomedicine (IRB), 08024 Barcelona, Spain \\ 4 Catalan Institution for Research and Advanced Studies. Pg. Lluís Companys 23, 08010 Barcelona, Spain \\ 5 Department of Medicine, University of California San Diego, San Diego, CA 92103, USA; \\ jjenks@health.ucsd.edu \\ 6 Clinical and Translational Fungal-Working Group, University of California San Diego, \\ La Jolla, CA 92093, USA; mhoenigl@ucsd.edu \\ 7 Division of Infectious Diseases and Global Public Health, Department of Medicine, University of California \\ San Diego, La Jolla, CA 92093, USA \\ 8 Section of Infectious Diseases and Tropical Medicine, Department of Internal Medicine, Medical University \\ of Graz, 8036 Graz, Austria \\ 9 Department of Pulmonology, Kepler University Hospital, 4021 Linz, Austria; \\ helmut.salzer@kepleruniklinikum.at \\ 10 Division of Mycology, University of Çukurova, 01330 Adana, Turkey \\ 11 Institute of Hygiene and Medical Microbiology, Medical University of Innsbruck, 6020 Innsbruck, Austria; \\ cornelia.lass-floerl@i-med.ac.at \\ * Correspondence: milkit@cu.edu.tr (M.I.); david.perlin@hmh-cdi.org (D.S.P.); \\ Tel.: +90-532-286-0099 (M.I.); +1-201-880-3100 (D.S.P.)
}

Received: 3 August 2020; Accepted: 3 December 2020; Published: 8 December 2020 updates

\begin{abstract}
The high clinical mortality and economic burden posed by invasive fungal infections (IFIs), along with significant agricultural crop loss caused by various fungal species, has resulted in the widespread use of antifungal agents. Selective drug pressure, fungal attributes, and host- and drug-related factors have counteracted the efficacy of the limited systemic antifungal drugs and changed the epidemiological landscape of IFIs. Species belonging to Candida, Aspergillus, Cryptococcus, and Pneumocystis are among the fungal pathogens showing notable rates of antifungal resistance. Drug-resistant fungi from the environment are increasingly identified in clinical settings. Furthermore, we have a limited understanding of drug class-specific resistance mechanisms in emerging Candida species. The establishment of antifungal stewardship programs in both clinical and agricultural fields and the inclusion of species identification, antifungal susceptibility testing, and therapeutic drug monitoring practices in the clinic can minimize the emergence of drug-resistant fungi. New antifungal drugs featuring promising therapeutic profiles have great promise to treat drug-resistant fungi in the clinical setting. Mitigating antifungal tolerance, a prelude to the emergence of resistance, also requires the development of effective and fungal-specific adjuvants to be used in combination with systemic antifungals.
\end{abstract}

Keywords: antifungal resistance; azole; echinocandin; antifungal susceptibility testing; whole-genome sequencing; therapeutic drug monitoring; identification 


\section{Introduction}

Fungi are among the most impactful eukaryotic microorganisms living on earth and are associated with enormous crop loss and also to the extinction of various life forms [1]. Apart from being ubiquitously found in the environment, numerous fungal species are considered as part of the normal flora found in different anatomical sites including skin, lung, genitourinary, oral and gastrointestinal tract, where they play an important role in human health [2]. When the immune system is impaired, commensal fungal species can turn into invasive pathogens, translocating systematically to develop invasive fungal infections (IFIs), which affect multiple organs and organ systems [3]. Although underestimated as a cause of infection in humans, fungi are associated with approximately 1.5 million deaths and 1.7 billion superficial infections yearly, resulting in an enormous economic burden [4]. The impacts of fungi on human health go beyond acute and chronic infections, and new lines of study have linked some fungal species colonization to pancreatic cancer progression [5] and alcoholic cirrhosis [6], and we anticipate that future studies using new technologies will unravel unimaginable involvement of fungi in human health.

Fungal species belonging to Candida, Aspergillus, Cryptococcus, and Pneumocystis genera are the most clinically relevant pathogens causing IFIs [4]. Unlike the numerous classes of antibiotics used to treat bacterial infections, antifungals are limited in number and belong to three main classes, including azoles (fluconazole, itraconazole, voriconazole, posaconazole, etc.), echinocandins (caspofungin, micafungin, and anidulafungin), and polyenes, such as amphotericin B (AMB) [7]. Azoles bind to Erg11 in Candida and Cyp51A in Aspergillus species and interrupt the production of ergosterol, a critical sterol component of the fungal cell membrane, while echinocandins target the catalytic subunit of $\beta-1,3$-D-glucan synthase, encoded by FKS genes and interfere with $\beta$-1,3-D-glucan production, a major cell wall structural component [7]. Lastly, polyenes bind to ergosterol in the cell membrane and cause cell death through the formation of large pores on the cell membrane, which leads to interruption of osmotic pressure [7]. Antifungals can be either fungicidal, where the antifungal agent causes fungal cell death, or fungistatic, where the antifungal drug arrests cell proliferation but does not kill the fungal cell, such as fluconazole against Candida and echinocandins against Aspergillus species. Currently, mold-active triazoles, including voriconazole, posaconazole, and isavuconazole, and echinocandins, especially micafungin and caspofungin, are recommended first-line antifungals used to treat invasive Aspergillus and Candida infections, respectively $[8,9]$. Polyenes are used with caution due to the potential for nephrotoxicity and hepatotoxicity and are used more commonly to treat refractory Candida and Aspergillus infections. Echinocandins are insensitive against Cryptococcus neoformans [10]. Therefore cryptococcal infection treatment often involves amphotericin B, 5-fluorocytosine, and fluconazole [11]. Azoles are not the drug of choice for the treatment of Pneumocystis pneumonia (PCP), and alternative treatments include dapsone plus trimethoprim, clindamycin plus primaquine, atovaquone, pentamidine, or caspofungin [12]. Moreover, chemoprophylaxis and treatment with trimethoprim-sulfamethoxazole (TMP-SMX) have been associated with a significant reduction of mortality rate among HIV-infected and non-HIV-infected immunocompromised host suffering from PCP $[12,13]$. Considering the involvement of host- and drug-related factors affecting the antifungal therapeutic failure [14], the emergence of resistance to one antifungal agent can be devastating and severely limit the number of antifungals available to treat IFIs [15].

Prior to the extensive use of antifungals in the clinic (and fungicidal azoles in the environment), epidemiological studies showed the predominance of fungal species almost entirely susceptible to all classes of antifungals. Widespread use of antifungals has altered the epidemiological landscape of IFIs, where fungal species showing resistance to one and/or multiple classes of antifungals are increasingly identified in clinical settings and associated with therapeutic failure [16-19]. The most notable examples are the worldwide emergence of triazole-resistant Aspergillus fumigatus [16,19,20], Candida tropicalis, Candida parapsilosis [18], and multidrug-resistant (MDR) Candida auris [21] and the increasing prevalence of MDR Candida glabrata, especially in the U.S. [22]. Beyond Candida and 
Aspergillus, a growing body of evidence for Pneumocystis indicates that resistance develops in patients receiving sulfa prophylaxis and trimethoprim-sulfamethoxazole [23].

Finally, azole therapeutic failure has been recorded among patients with cryptococcal meningitis during the course of azole therapy [24,25]. Antifungal therapeutic failure can be due to host-, drug-, and fungal-related attributes [26]. For instance, various host underlying conditions, such as abdominal and liver abscesses, prevent the favorable penetration and distribution of antifungal drugs to the site of infection and the resultant suboptimal exposure to antifungal agents promotes survival and emergence of antifungal-resistant fungi $[27,28]$. Similarly, fungistatic drugs allow fungi to survive in the presence of an antifungal agent, which provides a window for fungi to acquire resistance [7]. Lastly, fungal attributes, such as, but not limited to, acquisition of resistance mutations in the drug target and biofilm formation, allow the fungi to thrive regardless of being exposed to antifungal drugs $[7,15]$. Of note, resistance to antifungals can be either acquired, where the fungi become resistant during antifungal therapy, or intrinsic, such as Candida krusei, which is intrinsically resistant to azoles like fluconazole.

In this review, we summarize the burden of antifungal resistance in the major fungal species associated with IFIs, define the cellular mechanisms underlying antifungal resistance, discuss the phenotypic methods used to distinguish susceptible and resistant fungal isolates, and explore how the application of new technologies, such as whole-genome sequencing, can impact the current paradigms of clinical practice and further of our understanding of antifungal resistance mechanisms. Finally, we address the clinical importance of therapeutic drug monitoring and new antifungal agents in late-stage clinical development and their role to potentially overcome clinical drug resistance. Of note, biofilms, which play an important role in drug resistance, have been extensively reviewed [29-33] and will not be discussed here.

\section{Epidemiology and Burden of Antifungal Resistance in Clinically Important Fungi}

The epidemiology of candidemia and invasive candidiasis, as well as aspergillosis, has been the subject of numerous studies over the years looking to define the scope of fungal burden and antifungal resistance on a global scale. In this context, different studies have investigated the epidemiological trends in Candida species infections in which only five species account for $92 \%$ of cases of candidemia-Candida albicans, C. glabrata, C. tropicalis, C. parapsilosis, and C. krusei. However, their distribution varies in population-based studies performed depending on the geographical areas (Table 1 and Figure 1) [34]. In a recent work, more than 15,000 invasive Candida isolates collected from 39 different countries throughout 20 years were included in a prospective antifungal susceptibility study to analyze the rate of echinocandin and azole resistance. As in the majority of the studies, C. glabrata was the most commonly detected non-C. albicans (NAC) species, except in Latin American and some Asian countries, where the NAC predominant species are C. parapsilosis and C. tropicalis [18]. The most recent ARTEMIS study revealed an increasing trend with respect to the prevalence of C. glabrata and C. parapsilosis. The third and fourth species more commonly isolated, C. tropicalis and C. krusei, maintained more steady numbers during the time period studied. Finally, the frequency of other Candida species showed an increase of almost 6\% [18]. Interestingly, despite being identified as a new agent of candidiasis within the decade, MDR C. auris has become increasingly identified as a cause of candidiasis in numerous countries. Shockingly, countries [35] such as India [36] and South Africa [37] have shown a dramatic increase in the prevalence of candidemia due to this MDR Candida species. Of particular concern is the tendency of this species to cause clonal outbreaks in clinical settings [38-41], which likely reflects its resilience on the skin and hospital surfaces, possibly due to biofilm production [42]. These findings support the results obtained in other reports in terms of species prevalence and antifungal resistance [43-46]. High rates of fluconazole-resistant C. glabrata $(2.8-6.8 \%)$ have been reported, together with an increase in C. parapsilosis $(0.6-4.6 \%)$, and C. tropicalis $(1.1-9.2 \%)$ fluconazole-resistant isolates, apart from the intrinsically fluconazole-resistant species, such as C. krusei and C. auris [18]. It is noteworthy that although the worldwide azole resistance rate 
seems low, such data are extremely worrisome at the institutional level, and not all countries are represented in the ARTEMIS study. Examples are the high level of fluconazole-resistant C. parapsilosis isolates in Turkey [47] and South Africa [48], C. tropicalis in Taiwan [49], C. auris in South Africa [37], and A. fumigatus in the Netherlands [50].

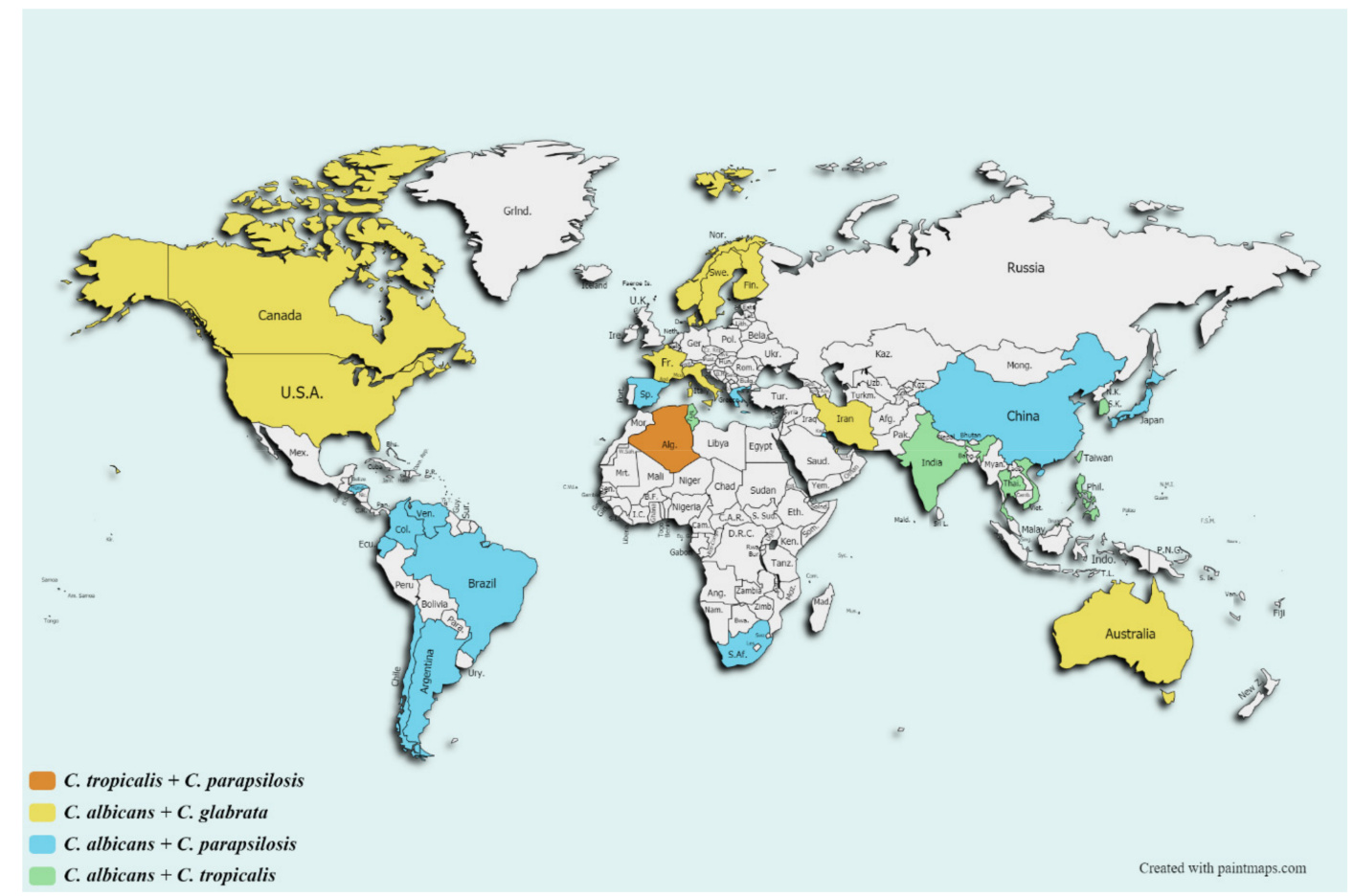

Figure 1. Worldwide prevalence of non-albicans Candida species causing candidemia.

The in vitro susceptibility of Cryptococcus can vary according to serotype, geographical origin and population being studied. Increasingly there are reports of Cryptococcus isolates with high azole MIC values, although the correlation of high MICs on clinical outcome is uncertain [51,52]. Clinical breakpoints have not been established for Cryptococcus species, although epidemiological cut-off (ECOFF) values have been proposed for some antifungal drugs to differentiate wild-type (WT) from non-wild-type (non-WT) isolates [51], which may result in clinical failure [53].

A systematic review of fluconazole resistance, including a total of 4995 Cryptococcus isolates from 3210 patients, showed a mean fluconazole resistance of $10.6 \%$ (95\% CI: 5.5-15.6) [54]. Relapse isolates showed higher rates of resistance by up to $24 \%$. The vast majority of studies included in the systematic review (28 of 29 studies) defined an ECOFF value of at least $\geq 16 \mu \mathrm{g} / \mathrm{mL}$ as fluconazole-resistant. MICs above the ECOFF value were reported in 936 of 4995 (18.7\%) isolates. Rates of resistance to 5-fluorocytosine among clinical isolates are lower compared to fluconazole [55,56].

Since $P$. jirovecii does not grow in vitro, studies investigating the prevalence of resistance from respiratory samples in HIV-infected and non-HIV-infected immunocompromised patients have mostly employed sequencing and mutation screening in genes involved in drug resistance, including MT85, SOD, DHFR and DHPS [57]. The most frequent ones are DHFR312, DHPS165 and DHPS171, but the prevalence of DHPS and DHFR mutations varies significantly, ranging from $0 \%$ up to $50 \%$ depending on HIV-status and geographical region [58,59]. Most sequence data are coming from single-centers with a limited number of $P$. jirovecii samples. However, the vast majority of data indicate a low prevalence of DHPS and DHFR mutations between $0 \%$ and $6 \%[60,61]$. 
Table 1. The epidemiology of candidemia and invasive aspergillosis and antifungal resistance rates determined for selected Candida species and Aspergillus fumigatus.

\begin{tabular}{ccccc}
\hline Species & $\begin{array}{c}\text { Prevalence } \\
\mathbf{( \% )}\end{array}$ & $\begin{array}{c}\text { Azole Resistance } \\
\text { Rate (\%) }\end{array}$ & $\begin{array}{c}\text { Echinocandin } \\
\text { Resistance Rate (\%) }\end{array}$ & References \\
\hline C. albicans & $>20.9-70$ & $0-7.8$ & $0-7$ & {$[43,44,46,48,62-87]$} \\
\hline \multirow{2}{*}{ C. glabrata } & $<15$ & $0-21$ & $0-23.1$ & {$[48,62,67,69,70,74-76,78,84]$} \\
\cline { 2 - 5 } & $15-38$ & $0-76$ & $0-100$ & {$[43,44,46,63,66,68,71,73,77,79-83,85-87]$} \\
\hline \multirow{2}{*}{ C. tropicalis } & $<10$ & $0.6-31.5$ & $0-8$ & {$[62-67,69-71,82,83]$} \\
\cline { 2 - 5 } & $10-49$ & $0-66.6$ & $0-10$ & {$[43,44,46,48,68,72-81,84-87]$} \\
\hline \multirow{2}{*}{ C. parapsilosis } & $<15$ & $0-8.3$ & $0-10.8$ & {$[46,62,63,77-82,85]$} \\
\cline { 2 - 5 } & $15-37$ & $0-53$ & $0-1.6$ & {$[43,44,48,65,71,73-76,83,84,86,87]$} \\
\hline C. auris & $0-14$ & $>90-100$ & $0-40$ & {$[38,62,88-91]$} \\
\hline A. fumigatus & $33.2-92$ & $<2-30$ & 0 & {$[92-102]$} \\
\hline
\end{tabular}

Acquired echinocandin resistance was found to have increased as well $[34,103,104]$. In the most updated report, the overall resistance rate to one or more echinocandins was lower for most of the Candida species, except for C. glabrata and C. tropicalis [18]. In contrast to the increasing resistance trend for azoles and echinocandins, several reports showed a broad activity for amphotericin $B$ and no indication of acquired resistance in the species aforementioned [46,105].

Regarding antifungal resistance in Aspergillus species, the global emergence of triazole resistance among both clinical and environmental isolates has been increasingly encountered worldwide in the past two decades. In this context, A. fumigatus is the main etiologic agent of aspergillosis $[100,101,106]$. The resistance rate for azole-resistant $A$. fumigatus varies dramatically by both geographic region and patient cohort and is more prevalent among certain high-risk patient populations $[93,107,108]$, ranging from less than $2 \%$ in most of the cases to $30 \%$ in some studies which just include hematology and ICU patients [92-95]. Finally, other human pathogens species of the Aspergillus section Fumigati also show azole resistance, such as A. lentulus, A. viridinutans, A. fumigatiaffinis and Neosartorya pseudofischeri, but due to its prevalence, they do not represent as a notorious global threat as A. fumigatus infections $[103,109]$. Therefore, the epidemiological changes and the increased incidence of fungal species exhibiting intrinsic and acquired resistance emphasize the importance of continued surveillance; thus, the proper management of these infections will ultimately lead to improving patient quality of life and survival $[18,46]$.

\section{Mechanisms of Antifungal Resistance}

\subsection{Antifungal Tolerance}

Before discussing the mechanisms employed by fungi to counteract the inhibitory functions of antifungal agents, it is important to distinguish the concepts of antifungal tolerance and resistance.

Antifungal resistance refers to stable genetic changes of a fungal pathogen for a specific class of antifungal drug that results in an increased probability for therapeutic failure. Standardized in vitro antifungal susceptibility testing (AFST) provides a surrogate measure for this potential with drug and organism-specific resistance breakpoints, which take into account mechanism of action, pharmacodynamic responses in animal model systems and clinical response [7]. Antifungal tolerance typically refers to non-heritable cellular adaptations that enable a subpopulation of cells exposed to drugs to persist. Tolerance involves a complex circuitry of signal transduction pathways leading to a rapid and coordinated response to an exogenic agent threatening the cellular integrity and refers to fungal growth higher than susceptible minimum inhibitory concentration (MIC) range in standardized testing. Unlike antifungal resistance, tolerance is a reversible phenomenon meaning that antifungal tolerant cells return to the susceptible MIC range when re-cultured [7]. Pathways involved in tolerance vary depending on the antifungal agents used. For instance, high osmolarity glycerol 
(HOG), protein kinase C (PKC), and calcineurin are involved in tolerance against echinocandins, which is referred to as cell wall integrity pathway, while PKC and calcineurin are involved in tolerance against azoles, which is defined as membrane integrity pathway [7]. Of particular importance in antifungal tolerance is the heat-shock protein 90 (HSP90), which plays an important role by stabilizing key components of the tolerance, i.e., PKC and calcineurin $[110,111]$. Therefore, utilization of fungal-specific HSP90 inhibitors in combination with antifungal drugs may have a role as an alternative strategy to effectively combat against the drug-resistant isolates in both molds and Candida [110-112]. Similarly, combination calmodulin inhibition (fluphenazine) and caspofungin against $C$. glabrata strains carrying F659del in hotspot1 of Fks2p decreased caspofungin MICs, thermotolerance, and the biofilm formation of the strains tested [113]. Similarly, a recent study identified a new protein kinase inhibitor, 2,3-aruyl-pyroazolopyridine, which can abrogate echinocandin resistance of $C$. albicans strains when used in combination with caspofungin [114]. The combination of an echinocandin with an inhibitor of the main components of stress regulatory points to an important route to help overcome and prevent emergence. Although once regarded as an azole AFST artifact, "trailing edges" provide insights into drug tolerance. Newer studies have highlighted the importance of antifungal tolerance and have linked tolerance to both antifungal therapeutic failure and mortality $[115,116]$. It is now considered a window to drug resistance emergence [117].

When the fungus is exposed to antifungals, tolerance pathways allow cells to persist. The cell's DNA repair system leads to the occurrence of genetic mutations throughout the genome, especially the drug-target, which is under high selection pressure permits the establishment of stable drug-resistant fungal isolates [22]. Recently, it was observed that almost $35 \%$ of $C$. tropicalis blood isolates showed a high-level of fluconazole tolerance ( $\geq 50 \%$ of drug-free control), among which almost one-third of infected patients showed therapeutic failure when treated with fluconazole [118]. Moreover, significant variation in tolerance observed among clinical isolates has been associated with a difference in genetic backgrounds [119], which may reflect the mutagenesis potential of a given isolate to induce resistance [22]. Indeed, it was found that some microsatellite clusters contained a significantly higher number of high fluconazole-tolerant $C$. tropicalis isolates and vice versa [118]. Unfortunately, despite that there is extensive knowledge about antibiotic tolerance in clinically important bacterial species, our current understanding of antifungal tolerance is still in its infancy. These studies emphasize the clinical significance of antifungal tolerance, and it is recommended to consider the level of tolerance observed ( $\geq 50-75 \%$ of drug-free control) when choosing an antifungal agent in the clinic [116,118]. It is noteworthy that the existing inhibitory compounds used against stress pathways employed by human fungal pathogens are already used in the clinic and have a profound impact on the host by impairing immune functions $[112,120]$.

\subsection{Azole Resistance}

\subsubsection{Azole Resistance in the Candida Genus}

Antifungal resistance mechanisms vary depending on the species and the antifungal agents. Generally, changes in drug affinity at the drug target for azoles and echinocandins and overexpression of the drug target and efflux pumps are the major determinants of azole resistance. Considering that azoles are the main drug used to treat invasive candidiasis in developing countries [63,91,121-123], having a clear understanding of resistance mechanisms is of paramount importance (Figure 2). Although modification of the drug target, ERG11, is an important azole resistance mechanism in species belonging to CTG (C. albicans, C. parapsilosis, C. tropicalis) and Metschnikowia clades (C. auris) [47,124-126], it does not play a prominent role in C. glabrata [121,127], which is phylogenetically located within the whole-genome duplication (WGD) clade. Heterologous expression and comparative sequencing studies have identified Y132F, K143R, G458S (similar to G464S) as the most prevalent amino acid substitution profoundly impacting the azole susceptibility profiles in CTG and Metschnikowia 
clades [47,124-126]. Of note, there also seems to exist a link between specific mutations in ERG3 and azole resistance in C. parapsilosis [128].

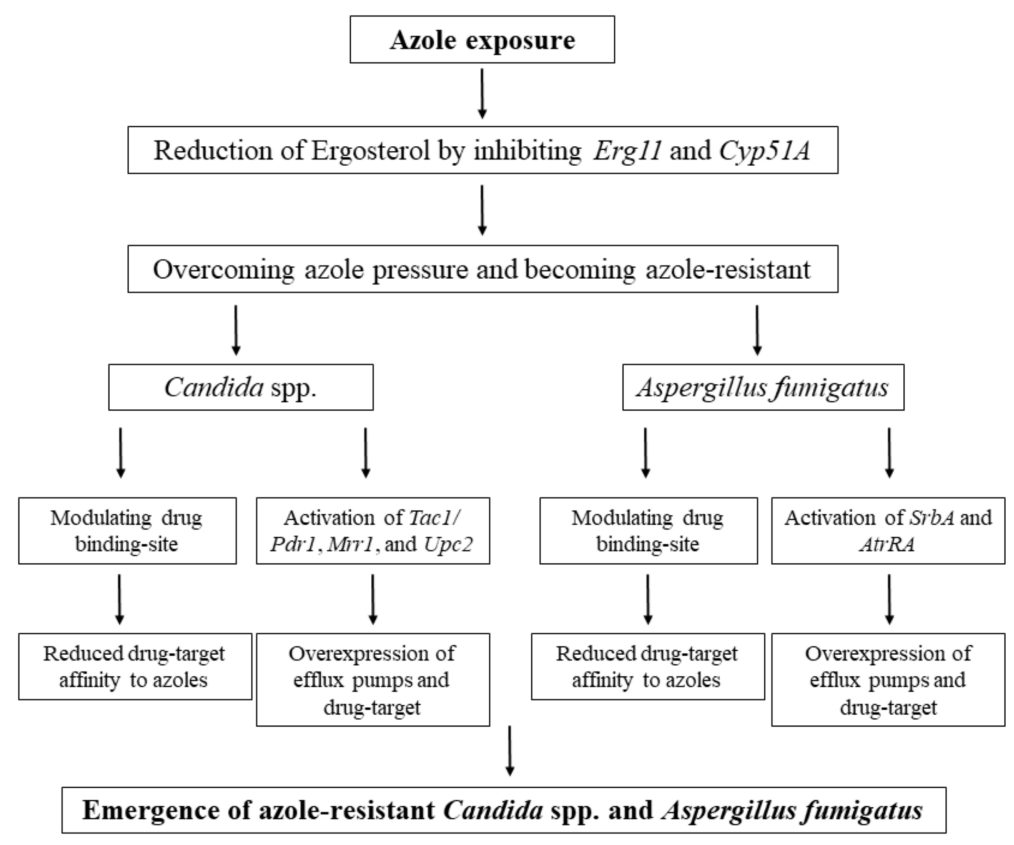

Figure 2. General mechanisms of azole resistance mechanisms employed by Candida and Aspergillus species covered in this study. The drug-target modulating and overexpression of efflux pumps and drug target are the most common strategies counteracting the azole efficacy used by these species.

Overexpression of drug target and efflux pumps, on the other hand, appears to be a conserved response to azole drugs among species within the three aforementioned clades. Overexpression of ERG11, which is controlled by a zinc cluster transcription factor (UPC2), results in a higher functional copy number of the drug target and a higher concentration of ergosterol to keep up with the overwhelming concentration of azole drugs [124]. The occurrence of gain-of-function (GOF) mutations, especially in the C-terminal domain of Upc2, results in its structural changes in the ligand-binding domain and its constitutive hyperactivity, followed by nuclear translocation, where it binds to the binding motifs upstream of ERG11, subsequently leading to ERG11 overexpression and overproduction of ergosterol [124,129]. Although its role remains to be elucidated in C. auris, C. tropicalis, and C. parapsilosis, Upc2 can bind to the promoter of PDR1 and CDR1 in C. glabrata [130]. Furthermore, a recent study unveiled a new transcription factor, $C g R p n 4$, which through the overexpression of genes involved in ergosterol biosynthesis pathways, especially ERG11, plays an important role in membrane homeostasis, ergosterol biosynthesis, and azole resistance in C. glabrata [131]. Chromatin immunoprecipitation assay revealed that $C g R p n 4$ directly binds to the TTGCAAA binding motif located upstream of ERG11 [131].

Overexpression of efflux pumps is a common response when fungi are stressed with azoles [124]. Major efflux pumps implicated in azole resistance belong to two major categories, ATP-binding cassette (ABC) transporters (CDR1 and CDR2) and major facilitator superfamily (MFS) transporters (MDR1 and MDR2) [132], mainly regulated by transcription factors Tac1 and Mrr1, respectively [124]. Despite being common in C. albicans [124], the association between GOF mutations in TAC1 and MRR1 and the resultant overexpression of $C D R 1$ and MDR1 are poorly studied in C. parapsilosis, C. tropicalis, and C. krusei. Therefore, comprehensive cataloging of UPC2, TAC1, and MRR1 in these Candida species, followed by their assessment in azole resistance, seems to be a missing knowledge gap in these Candida species [133]. Recently, a number of studies cataloged mutations occurring in UPC2, TAC1, and MRR1 in azole-resistant C. tropicalis and C. parapsilosis isolates [47,118,122,134-136], which could 
serve as a basis to broaden our understanding of azole resistance mechanisms in C. parapsilosis and C. tropicalis. New lines of studies identified a prominent role of GOF mutations in TAC1B for azole resistance in C. auris [111,137]. As for C. glabrata, several studies have identified specific GOF mutations throughout the PDR1 gene in clinical isolates of C. glabrata resistant to azoles [27,127,138,139]. Importantly, the occurrence of such mutations is not only associated with an overexpression of efflux pumps and azole resistance but also a higher virulence due to immunoevasion of C. glabrata during infection [140,141]. Interestingly, it has been shown that some genes implicated in adhesion, EPA3, also play roles in azole resistance by indirectly reducing the intracellular concentration of azole drugs in serially collected clinical isolates of C. glabrata [139]. Collectively, these studies suggest that mechanisms of azole resistance are complicated and also poorly addressed in some Candida species. In light of the increasing prevalence of azole-resistant C. parapsilosis and C. tropicalis in numerous countries [18], addressing these mechanisms will have significant implications in drug discovery and the efficacious management of infected patients.

\subsubsection{Azole Resistance in A. fumigatus}

Azole resistance in A. fumigatus is also a multifactorial phenomenon involving the modification and overexpression of the azole drug target, Cyp51A, and overexpression of efflux pumps, mainly Cdr1B and AtrF [142]. Most prominently, azole resistance results from the occurrence of 34 and $46 \mathrm{bps}$ tandem repeats $\left(\mathrm{TR}_{34}\right.$ and $\mathrm{TR}_{46}$ ) upstream of $\mathrm{Cyp51A}$, which appear to serve as extra binding sites for sterol regulatory element-binding element protein ( $\mathrm{SrbA}$ ) and $\mathrm{ABC}$ transporter-regulating transcription factor A (AtrRA) [142]. TR duplications are thought to have an environmental origin and are typically accompanied by mutations in Cyp51A open reading frame, such as $\mathrm{TR}_{34} / \mathrm{L} 98 \mathrm{H}$ and $\mathrm{TR}_{46} / \mathrm{Y} 121 \mathrm{~F} / \mathrm{T} 289 \mathrm{~A}$, which are also the most prevalent mutations found in azole-resistant clinical and environmental A. fumigatus isolates [142]. Recent studies have suggested that azole resistance implicated by SrbA and AtrR occurs via overexpression of Cyp51A and Cyp51A and Cdr1B, respectively [143,144]. CCAAT-binding elements, including $\mathrm{HapB}, \mathrm{HapC}$, and HapE, bind downstream of the AtrR and SrbA binding sites and negatively regulate Cyp51A expression. Strains containing HapE ${ }^{\mathrm{P} 88 \mathrm{~L}}$ were shown to be associated with azole resistance in A. fumigatus clinical isolates lacking Cyp51A mutations [145,146]. A recent study showed that a laboratory-generated voriconazole-resistant Aspergillus flavus isolate carried an amino acid substitution in Yap1 ${ }^{\mathrm{L} 558 \mathrm{~T}}$, which was associated with an overexpression of AtrF and voriconazole resistance [147]. New studies implicating various cellular components and pathways involved in azole resistance resulted in significant advances on the topic of azole resistance in A. fumigatus [148-151].

\subsection{Echinocandin Resistance}

Unlike complicated resistance mechanisms for azoles involving numerous components, echinocandin resistance is dominated by a single mechanism of action involving mutations in hotspots (HS) regions of FKS genes encoding amino acid substitutions within the catalytic subunits of $\beta-1,3-D-g l u c a n$ synthase [152,153]. As discussed above, echinocandin resistance is relatively rare $(<1-2 \%)$ in C. albicans clinical isolates $[18,124]$. However, more significant echinocandin resistance (2-10\%) occurs in C. glabrata, C. tropicalis, and C. auris [18,21]. Epidemiological studies have shown that S629P/T and S663P/F/A are the most observed amino acid substitutions in HS1 of Fks1 and Fks2, respectively, and they are linked to high echinocandin MIC values in clinical isolates of C. glabrata [133,154]. Among C. albicans isolates, S456P/F and Ser641P/F are the most prevalent resistance-associated mutations, although other HS1 and HS2 mutations do occur [155]. S645P and S639P/F/Y seem to be the most predominant amino acid substitutions observed in HS1 of Fks1 in echinocandin-resistant clinical isolates of C. tropicalis and C. auris, respectively [133]. Clinical isolates of $C$. parapsilosis intrinsically have higher MIC values against echinocandins when compared to the other Candida species, which is due to a polymorphism P660A in the HS1 of Fks1 [156]. Since bona fide echinocandin-resistant C. parapsilosis isolates are rarely reported in clinical isolates [18], 
the respective resistance mechanism remains obscure. Interestingly, a recent report identified four micafungin-resistant C. parapsilosis blood isolates in Turkey, which harbored a novel amino acid substitution R658G in HS1-Fks1. These isolates were genetically related and resulted in caspofungin therapeutic failure in a patient infected with one of those isolates [157].

The fungistatic action of echinocandins on Aspergillus has deterred its broader use on invasive aspergillosis or chronic pulmonary aspergillosis, except for salvage therapy, often in combination with mold-active triazoles [158]. Therefore, echinocandin resistance is quite rare in clinical isolates of $A$. fumigatus, but the increasing prevalence of triazole-resistant $A$. fumigatus isolates have prompted enhanced use of echinocandin therapy with an expectation for the emergence of resistant isolates. As such, it was documented that F675S in HS1-Fks1 of a clinical A. fumigatus isolate was acquired following micafungin therapy, which subsequently resulted in therapeutic failure [153]. Interestingly, a new study identified echinocandin-resistant A. fumigatus isolates that did not harbor any mutations in the FKS gene. Authors found a reduction in sensitivity of $\beta-1,3-D-g l u c a n$ synthase to echinocandins, which was due to prominent lipid changes in the enzyme microenvironment mainly by dihydrosphingosine and phytosphingosine [159]. It is noteworthy that in some cases, mutations just outside of the HS regions can cause echinocandin resistance [160] and also occasionally, echinocandin-susceptible isolates harbor a weak mutation in HS regions that results in therapeutic failure [27]. Therefore, a combination of both FKS sequencing and AFST provides the most accurate results.

\subsection{Antifungal Resistance in Cryptococcus and Pneumocystis}

Azole resistance in Cryptococcus has been associated with ERG11 mutations and/ or overexpression of ERG11 and an ATP-binding cassette (ABC) transporter (AFR1). Combination of an efflux blocker (FK506, calcineurin inhibitor) with voriconazole showed four to eight times lower MICs than compared to voriconazole mono in C. neoformans multi-azole-resistant strains [161]. In multi-azole-resistant strains, the triazole ravuconazole (named BMS-207147 and ER-30346) showed efficacy against strains that encode a protein with a G344S substitution in ERG11 [162]. In C. neoformans, a small ( 1\%) heteroresistant subpopulation exists, which, when exposed to drugs, leads to selection and clonal expansion of resistant variants leading to fluconazole resistance [163]. Heteroresistant subpopulations are often not captured in standardized (CLSI or EUCAST) susceptibility procedures. Duplications of chromosome 1 (disomy) are often observed in this resistant subpopulation [164], although Cryptococcus undergoes dynamic ploidy changes in response to drug exposure leading to the selection of resistant variants. Resistance occurs due to increases in expression of resistance determinants on Chr1, including ERG11 and AFR1, encoding a major drug efflux transporter. Resistance emergence is related to drug exposure and occurs with the use of clinically relevant regimens but may be potentially overcome by dosage escalation or the use of combination therapy [165].

5-fluorocytosine resistance, on the other hand, is associated with mutations in the UXS1, FUR1 and FCY2 gens and alterations in capsule biosynthesis in C. neoformans [166,167]. The intrinsic echinocandin resistance of Cryptococcus is not FKS-related [168]. While the mechanism of resistance is not fully elucidated, it appears to involve the concerted involvement of CRM1 and CDC50 by maintaining cellular calcium homeostasis influencing a mechanosensitive lipid flippase [10], as well as melanin within the capsule, which may act by the complexing drug [169].

As explained above, azoles are not effective in PCP, which was primarily thought to be due to the uptake of sterol from the host lung [170]. However, new lines of studies showed that the ergosterol biosynthetic pathway is active, and ergosterol is also produced by $P$. jirovecii itself. Moreover, the presence of mutations in ERG11 has been linked to azole resistance in this species [171]. Furthermore, mutations inside two fungus-related genes, namely dihydrofolate reductase (DHFR) and dihydropteroate synthase (DHPS), result in enzyme active site structural changes, which are predicted to interfere with the substrate binding capacity, consequently leading to sulfa resistance [172,173]. Resistance evolves during therapy and can be acquired by 
person-to-person transmission [11,174]. DHPS mutation can affect clinical outcomes, including a longer duration of mechanical ventilation and increased mortality compared to patients with a wild-type genotype $[59,175,176]$. Moreover, higher frequencies of treatment-limiting adverse reactions were reported in patients with DHPS $[59,175,176]$. Therefore, DHPS and DHFR mutational analyses could represent a promising opportunity for optimal patient management, avoiding treatment failure, and finally, death due to PCP. However, more evidence is needed on the frequency of DHPS and DHFR in different patient cohorts and its real impact on clinical outcomes. In a recent pediatric study, phylogenetic analysis revealed 13 unique sequence types (ST), including STs in DHFR and DHPS, that were associated with treatment failures among PCP-positive patients [177]. Yet, this is not universal as a study evaluating a German patient cohort reported a low frequency of such mutations [60].

\section{Antifungal Susceptibility Testing: Current Paradigm, Challenges, and Solutions}

The need for antifungal susceptibility testing (AFST) reflects the increased number of patients having risk factors for invasive fungal infection, the widespread use of antifungals, the rise of acquired resistance, and finally, the emergence of new fungal pathogens [178]. The major goal of AFST is to provide MIC values to guide optimal antifungal therapy and to monitor the emergence and epidemiology of antifungal drug resistance, locally or internationally. However, the drug of choice may be empirically assumed by the proper identification of the fungus and its inherent drug susceptibility profile; hence AFST is recommended when the underlying infection is invasive, and antifungal drug resistance is suspected, or when therapy is failing [179]. The implementation of antifungal stewardship programs is highly recommended, and the current standards in patient care comprise species identification and the performance AFST in isolates collected from sterile body sites, such as blood [180].

Standardized reference methods, the broth microdilution according to the Clinical and Laboratory Standards Institute (CLSI) and the European Committee on Antimicrobial Susceptibility Testing (EUCAST) represent the gold standards for AFST, but they are time-consuming and labor-intensive [179,181-184]. Alternative tests or commercial products include disk diffusion, epsilometer tests, colorimetric broth microdilution, and automated spectrophotometric systems [178]. Recently, a new low-cost four-well plate agar method is suitable for echinocandin susceptibility screening of Aspergillus species and can be used to detect echinocandin non-WT isolates [185]. Moreover, MIC test strip and Sensititre YeastOne showed an overall agreement of $>72 \%$ and $>94 \%$ at \pm 1 and \pm 2 dilutions when compared to CLSI and EUCAST broth microdilution methods, respectively [186].

All these AFST methods display a variety of specific advantages and disadvantages. In general, AFST is time-consuming as providing MICs usually takes $24-48 \mathrm{~h}$ from the time point culture is available. In addition, the interpretation of results may be difficult for fungi where clinical breakpoints are lacking. The lack of interpretive criteria for various fungus-antifungal combinations raises the question of how to deal with such data and implement them in clinical practice [181]. Besides these practical issues, it should be noted that technical (aerobic environment, high glucose, planktonic cells, growth media), as well as fungal factors (a mixture of hyphae, conidia and fungal biofilms, fungal virulence and fitness) may influence MIC readings [187]. Of note, P. jirovecii does not grow on culture media in vitro, which precludes the utility of AFST for PCP.

New approaches to aid AFST target culture-independent techniques, such as MALDI-TOF MS technology and molecular-based resistance detection. The call for molecular-based susceptibility testing is growing, which aims to detect validated genetic resistance mechanisms. Such analyses may provide results within a few hours, but various limitations (detailed in Section 5) may complicate interpretation [178]. Some MALDI-TOF MS assisted AFST methods have been evaluated for a limited number of fungal species and drugs [188,189]. The MALDI-TOF MS is promising but needs a simplified, automated method for testing a broad range of fungi and antifungals. 


\section{Emerging Molecular Approaches to Diagnose Resistance, Current State and Challenges}

The ability of a fungal cell to stably resist drug exposure and transfer it to its progeny is encoded in its genome [190]. This fact implies that, if the genetic determinants of resistance are known, a genetic test can be developed to detect the presence of such a trait. This is the norm for assessing drug susceptibility in viruses and many bacteria. Similarly, for medical mycology, this is a very promising approach given the significant investment of time necessary to perform standard drug susceptibility testing (discussed in Section 4). In addition, the availability of molecular approaches to amplify or probe specific DNA sequences, as well the continuous developments in next-generation sequencing (NGS), are paving the way for more specific, accurate, and cost-effective approaches [191]. Despite much progress, these approaches have achieved limited implementation in clinical mycology [191-193].

A major limitation of molecular approaches for the diagnosis of resistance is that the same resistance phenotype can be caused by mutations at different loci $[27,123,140]$. Thus, previous knowledge of the resistance-causing mutations is a prerequisite for developing an accurate technique. Once a set of resistance-conferring mutations is known, specific tests for their presence can be developed based on PCR amplification of nucleic acid hybridization approaches, or whole-genome sequencing data can be compared to a database of known mutations [191]. All these approaches have been successfully used for different Candida and Aspergillus pathogens [194-198]. Along the same line, commercial real-time PCR assays have been developed for the identification of DHPS mutations [199]. As discussed in Section 3, this knowledge is highly limited for fungal pathogens such as C. parapsilosis and C. tropicalis [133], but, as research progresses, this gap is expected to be closed, at least for the most common pathogens. Probe-based approaches have higher specificity and are thus promising for direct resistance screening of clinical specimens. However, they require a catalog of known resistance-conferring mutations, which is only partially available even for the best-studied species. The more incomplete that catalog of resistance-conferring mutations is, the more false-negatives will this test produce. Direct sequencing approaches allow the discovery of novel mutations-although they still require independent validation linking a genetic change to the resistance phenotype for application. Whole-genome sequencing can provide very accurate results in organisms for which the resistance-conferring mechanisms are well understood. For instance, a genomic survey of bacterial isolates recovered from clinical samples has shown an excellent categorical agreement with standard antimicrobial susceptibility testing [200,201]. Using this standard, echinocandin resistance among Candida species is ideally suited for resistance assessment, as is azole resistance among Aspergillus, as there is a strong correlation between clinical resistance, MIC and specific mutations in target genes [133]. Once a comparable level of knowledge is achieved for the different fungal pathogens and drugs, it is envisaged that a similar level of accuracy could be obtained.

Most applications explored so far have been focused on target sequencing of specific regions or whole-genome sequencing of isolates. However, emerging NGS applications include the direct sequencing of entire communities from clinical samples using a whole-genome shotgun approach coupled to a computer-based reconstruction of complete or partial genome sequences of the organisms present in the sample-, i.e., metagenomics [202,203]. For instance, independent of resistance, a recent study successfully employed a high-resolution metagenomics approach to a fecal sample using internal transcribed spacer 1 to predict candidemia [3]. Although more expensive and involving steeper requirements for downstream analyses, a metagenomics approach has several advantages. First, it is entirely unbiased and does not require a prior hypothesis on the infecting organism, whose identity and resistance potential can be diagnosed from the analysis of the sequencing reads. Second, as it is not based on a single isolate, it can inform on the genetic diversity of the infecting population at the sampled sites. Lastly, in addition to the information on the infecting agent, it can provide information on the host and the entire microbial community present in the sample site, which can also have clinical relevance [204]. Increasing throughput and cost-effectiveness of sequencing machines and the emergence of long-read sequencing technologies, such as oxford nanopore, are making metagenomics approaches more affordable and informative. One could envision a metagenomic approach being used 
in a prognostic manner, surveying stool, blood, or saliva samples from patients in order to monitor the presence of drug-resistant microbes and thereby anticipate treatment failure and allowing or preparing for therapy adjustments before a systemic infection with a resistant strain appears.

All these promising developments notwithstanding, the implementation of NGS technologies in a clinical setting is still very far from being routine. There are many challenges that need to be overcome, including cost, time, equipment and expertise [159]. Although sequencing costs and even sequencing equipment is decreasing, the bulk of the cost for NGS applications is related to both sample preparation (DNA extraction, library preparation) or to bioinformatics analysis of the data. Both procedures require either highly trained personnel or costly automated alternatives. In addition, the amount of time elapsed from sample collection to specific information needs to be minimal $(<24 \mathrm{~h})$ to facilitate clinical value. This (and possibly some ethical considerations) limits outsourcing analyses to most external providers. Finally, although NGS provides a wide array of interesting information that could be exploited in the future, in the clinic, this information needs to be highly focused and processed to provide direct answers to specific clinical questions so that clinicians can quickly react to the data instead of being overwhelmed. Ideally, a clinical-grade NGS system should be encapsulated in the form of a fully or semi-automated device that processes a sample and outputs actionable data in the most direct and rapid way. Such devices, like the Cepheid Xpert MTB/RIF, have revolutionized the management of Mycobacterium tuberculosis (MTB) infections by providing faster and more accurate MTB diagnosis that detects MTB and rifampicin (RIF) resistance simultaneously [205]. The push for personalized medicine in other clinical fields such as cancer or rare diseases is driving the penetration of genomics in the clinic, and it is likely that current limitations, at least in terms of costs and resources, will eventually be overcome. In sum, as our knowledge of the genetic basis of antifungal resistance grows and matures, and as new molecular tools enter a mainstream microbial diagnosis, it is anticipated that the molecular detection of antifungal resistance will be an important component of clinical care.

\section{Therapeutic Drug Monitoring and Drug Dose Optimization}

The treatment of invasive fungal infections is often complex and complicated by multiple factors that may affect the absorption, distribution, and metabolism of antifungal agents, including predisposing factors for infection and the site and severity of the infection. Therapeutic drug monitoring (TDM) is utilized to measure antifungal drug levels to prevent inadequate dosing that may lead to the emergence of resistance and/or treatment failure or excessive dosing that may lead to drug toxicity. The major guidelines recommend TDM once a steady-state has been reached for triazole-based treatment for invasive aspergillosis (IA) and when extended courses of prophylaxis are used, including by the Infectious Diseases Society of America [9], European Society for Clinical Microbiology and Infectious Diseases (ESCMID) and the European Confederation of Medical Mycology (ECMM) [206], and the European Conference on Infections in Leukemia (ECIL) [207]. The European Respiratory Society (ERS) and ESCMID also recommend TDM for triazole-based treatment for chronic pulmonary aspergillosis [208]. The IDSA also recommends TDM with voriconazole during the treatment of invasive candidiasis (IC) [8], as does the ESCMID when 5-fluorocytosine, voriconazole, and posaconazole are used [209].

In vitro studies and animal modeling have shown that the area under the concentration-time curve and minimum inhibitor concentration (AUC/MIC) ratio is the pharmacokinetic/pharmacodynamics (PK/PD) index that is most predictive of posaconazole efficacy against yeasts [210]. In invasive mold infections, the time above the MIC (T>MIC) and the AUC/MIC ratio are particularly important with posaconazole antifungal therapy [211] and other triazoles [212], as well as for echinocandins. In an analysis of 6 of 10 clinical trials of patients receiving voriconazole, there was no association between voriconazole levels and treatment efficacy, though, because antifungal exposure far exceeded the MICs of most pathogens [213]. The peak concentration $\left(C_{\max }\right)$ and MIC are particularly important PK/PD indices for amphotericin B and the echinocandins [214]. Lastly, the T>MIC is the most relevant PK/PD indices for flucytosine [214]. 
While sub-therapeutic drug levels increase the risk for treatment failure, they also can increase the risk for resistance emergence with invasive fungal infections for patients on antifungal prophylaxis or extended treatment durations. For example, multiple studies have shown that sub-therapeutic trough concentrations during posaconazole prophylaxis in patients with hematologic malignancies are associated with breakthrough invasive fungal infections [215-217]. Studies of lung transplant recipients on prophylactic voriconazole have found higher rates of fungal colonization and breakthrough fungal infections [218] in those with sub-therapeutic voriconazole drug levels. In addition, higher rates of breakthrough fungal infections have been observed in patients with sub-therapeutic voriconazole levels following allogeneic stem cell transplantation in patients [219].

As stated above, acquired azole-resistance in A. fumigatus is becoming increasingly problematic [220-223], partly driven by the use of triazoles as environmental fungicides [224,225]. In addition to sub-therapeutic drug levels, increasing the risk of breakthrough invasive fungal infections, there is also a risk of causing increased antifungal resistance. In one study of patients with cystic fibrosis of an azole therapy, primarily being used for the treatment of allergic bronchopulmonary aspergillosis (ABPA), persistently positive fungal culture, or Aspergillus bronchitis, azole levels were sub-therapeutic in half of the patients, with an association between sub-therapeutic drug levels and increased antimicrobial resistance [226]. Even in the treatment of azole-resistant infections, using higher doses of voriconazole $[227,228]$ and posaconazole [229] has been shown to be effective in the treatment of these infections. Thus, the effective use of TDM may help prevent the emergence of drug-resistant fungal infections and facilitate the treatment of azole-resistant infections, possibly with higher doses of a given antifungal, although more investigation of this strategy is needed.

\section{Optimizing Therapy by Species Identification}

As discussed, fungal species respond differently to various antifungal agents; therefore, species identification plays a pivotal role in drug-decision-making practices, which is endorsed by standardized clinical treatment practices [8]. The most notable example is the stark azole susceptibility pattern observed between the highly susceptible C. albicans and inherently resistant C. krusei. Unfortunately, accurate and rapid identification tools, such as matrix-assisted laser desorption ionization time-of-flight and Sanger sequencing, which are common in Western countries, are largely unaffordable for most clinical laboratories of developing countries, and most of the identifications are performed by inaccurate and expensive phenotypic tools [123]. To help overcome this issue, a comprehensive multiplex PCR was introduced [230], which can identify the most clinically important yeast species causing infection in humans and numerous studies afterward showed its reproducibility in various epidemiological studies [92,231,232]. Although such techniques are far from ideal, their application can significantly shorten the turnaround time and improve the species identification accuracy. We hope that the future advances in technology and materials used in MALDI-TOF MS and Sanger sequencing offer affordable options to be used in developing countries.

\section{Therapeutic Challenges and how to Overcome Them}

New antifungal drugs have been scarce over the last decade, and only one new antifungal (a member of the class of triazoles) has been approved for clinical use. The urgency for new antifungal classes is growing as cases have increased, and as detailed above, once-treatable fungi are becoming resistant. Furthermore, only one approved class of antifungal drugs, the azoles, can be taken orally. Due to increasing resistance rates against azoles and echinocandins, invasive Candida infections have become more difficult to treat, given the limited number of classes of antifungals currently available. This limitation in antifungal treatment options was prominently highlighted by the emergence of C. auris, a multidrug-resistant species, which has been associated with outbreaks worldwide and led to clinical alerts to U.S. and European healthcare facilities [233,234]. In the U.S., $90 \%$ of C. auris isolates appear resistant to fluconazole, about $30 \%$ have been resistant to amphotericin $\mathrm{B}$, and less than $5 \%$ have been resistant to echinocandins, while about one-quarter of recent Indian isolates of 
C. auris were resistant to two or more classes of antifungals [233-235]. For the treatment of these highly resistant Candida species, approval of ibrexafungerp, a member of a new antifungal class, which, like the echinocandins, attacks the fungal cell wall, but does so by latching onto another part of glucan synthase, is eagerly awaited. Ibrexafungerp is currently evaluated in a clinical phase III trial [236] and shows excellent oral bioavailability, making the drug potentially very valuable for the longer-term or ambulant treatment of yeast infections resistant to azoles or in patients with contraindications against azoles. Rezafungin is a novel echinocandin, for which phase III clinical trials are about to start, which has a much longer half-life than other echinocandins, allowing it to be given via a once a week injection instead of daily $[237,238]$. Most importantly, it can be delivered at high dosages, which overcome certain types of echinocandin resistance. Rezafungin has improved activity against Aspergillus species compared to the other echinocandins and may, therefore, become an alternative option for treating azole-resistant aspergillosis [237].

The emergence of triazole resistance complicates the selection of appropriate antifungal treatment for invasive aspergillosis, where triazoles are considered the first-line treatment option [239-243]. Given that more areas may be burdened with high rates of environmental triazole resistance, triazoles may not be universally recommended as primary antifungal treatment, but instead, treatment choice may depend on the local epidemiology of azole-resistant $A$. fumigatus. While triazole resistance is considered an emerging threat for patients infected by A. fumigatus [244], leaving very limited treatment options for those patients, triazole resistance in Aspergillus terreus [245] may be even more threatening because $A$. terreus can be non-susceptible to amphotericin B. Liposomal amphotericin B is the primary alternative option to azoles for treatment of IPA, and therefore the drug of choice for treatment of azole-resistant aspergillosis, but as stated above nephrotoxicity may occur [9]. Alternative options for second-line treatment of azole-resistant aspergillosis are echinocandins, which show, however, reduced activity against Aspergillus when used as monotherapy [236]. In regions where environmental triazole resistance rates of Aspergillus exceed 10\%, primary treatment of all invasive aspergillosis cases with either liposomal amphotericin B or echinocandin-voriconazole combination has been recommended, with a later step down to voriconazole should the isolate show voriconazole susceptibility [183]. New antifungal classes currently under clinical development, including fosmanogepix, also known as APX001 is a first-in-class and orally available broad-spectrum antifungal agent, which targets the highly conserved Gwt1 fungal enzyme, and olorofim, which belongs to a new class of antifungals called the orotomides and targets dihydroorotate dehydrogenase in the de novo pyrimidine biosynthesis pathway) [246], have high potency against $A$. fumigatus without the same burden of drug-drug interactions and toxicity [247], and may therefore overcome the limitations of currently available antifungals for azole-resistant aspergillosis and become the preferred treatment options in the near future. Moreover, to accelerate drug development and accelerate regulatory approvals (e.g., Food and Drug Administration (FDA)), investigators are looking to repurpose existing FDA-approved compounds developed against other diseases with the hope of identifying efficacious new antifungal agents that can be rapidly deployed [248,249]. Interestingly, some of these compounds not only proved to be efficacious against drug-susceptible fungal species [248,249] but also some showed desired efficacy when tested on MDR Candida and mold species [250,251]. Therefore, the future battle against the drug-resistant fungal species in the clinic may benefit from comprehensive repurposing of FDA-approved compounds.

\section{Future Directions}

The increasing frequency of drug resistance in Candida and Aspergillus poses a serious threat to human health as there remains a limited number of systemic antifungal drugs available to treat IFIs. The increasing prevalence of azole resistance among invasive NAC species, especially C. parapsilosis and $C$. tropicalis, highlights a pressing need to better understand the underlying resistance mechanisms involved. Minimizing the global emergence of azole-resistant A. fumigatus isolates requires serious measures regarding antifungal stewardship in both agriculture and the clinic. Accordingly, 
the application of AFST, TDM, and accurate species identification is recommended as a part of routine antifungal drug decision-making. Finally, limited antifungal drug classes and the increasing presence of drug-resistant fungi should direct our efforts to continuously identify new drug classes with promising in vivo activities, preferably acting on cellular mechanisms apart from current systemic antifungals. New agents with novel mechanisms of action in late-stage clinical development will be welcome to help address this need. Furthermore, adjuvant drugs targeting HSP90-, PKC-, and calcineurin-inhibitors have the potential to limit drug tolerance to slow resistance emergence, and their development is encouraged.

Author Contributions: Conceptualization, A.A., M.I., and D.S.P.; writing-original draft preparation, A.A., T.G., R.G.-R., J.D.J., M.H., H.J.F.S., M.I., C.L.-F., D.S.P.; writing-review and editing, A.A., T.G., R.G.-R., J.D.J., M.H., H.J.F.S., M.I., C.L.-F., D.S.P. All authors have read and agreed to the published version of the manuscript.

Funding: A.A. and D.S.P. are funded by a grant from the National Institutes of Health (AI109025) to D.S.P.

Acknowledgments: We thank the critical review of Farnaz Daneshnia and her support with revision and paper preparation.

Conflicts of Interest: M.H. received research funding from Gilead and Pfizer. D.S.P. receives research support and/or serves on advisory boards for Amplyx, Cidara, Scynexis, N8 Medical, Merck, Regeneron, and Pfizer. The funders had no role in the design of the study; in the collection, analyses, or interpretation of data; in the writing of the manuscript, or in the decision to publish the results. The rest of the authors declare no conflicts of interest.

\section{References}

1. Fisher, M.C.; Gurr, S.J.; Cuomo, C.A.; Blehert, D.S.; Jin, H.; Stukenbrock, E.H.; Stajich, J.E.; Kahmann, R.; Boone, C.; Denning, D.W.; et al. Threats posed by the fungal kingdom to humans, wildlife, and agriculture. mBio 2020, 11, e00449-20. [CrossRef] [PubMed]

2. Rolling, T.; Hohl, T.M.; Zhai, B. Minority report: The intestinal mycobiota in systemic infections. Curr. Opin. Microbiol. 2020, 56, 1-6. [CrossRef] [PubMed]

3. Zhai, B.; Ola, M.; Rolling, T.; Tosini, N.L.; Joshowitz, S.; Littmann, E.R.; Amoretti, L.A.; Fontana, E.; Wright, R.J.; Miranda, E.; et al. High-resolution mycobiota analysis reveals dynamic intestinal translocation preceding invasive candidiasis. Nat. Med. 2020, 26, 59-64. [CrossRef]

4. Brown, G.D.; Denning, D.W.; Gow, N.A.R.; Levitz, S.M.; Netea, M.G.; White, T.C. Hidden killers: Human fungal infections. Sci. Transl. Med. 2013, 4, 165rv13. [CrossRef] [PubMed]

5. Aykut, B.B.; Pushalkar, S.; Chen, R.; Li, Q.; Abengozar, R.; Kim, J.I.; Shadaloey, S.A.; Wu, D.; Preiss, P.; Verma, N.; et al. The fungal mycobiome promotes pancreatic oncogenesis via activation of MBL. Nature 2019, 574, 264-267. [CrossRef] [PubMed]

6. Yang, A.M.; Inamine, T.; Hochrath, K.; Chen, P.; Wang, L.; Llorente, C.; Bluemel, S.; Hartmann, P.; Xu, J.; Koyama, Y.; et al. Intestinal fungi contribute to development of alcoholic liver disease. J. Clin. Investig. 2017, 127, 2829-2841. [CrossRef]

7. Berman, J.; Krysan, D.J. Drug resistance and tolerance in fungi. Nat. Rev. Microbiol. 2020, 18, 319-331. [CrossRef] [PubMed]

8. Pappas, P.G.; Kauffman, C.A.; Andes, D.R.; Clancy, C.J.; Marr, K.A.; Ostrosky-Zeichner, L.; Reboli, A.C.; Schuster, M.G.; Vazquez, J.A.; Walsh, T.J.; et al. Clinical Practice Guideline for the Management of Candidiasis: 2016 Update by the Infectious Diseases Society of America. Clin. Infect. Dis. 2016, 62, e1-e50. [CrossRef]

9. Patterson, T.F.; Thompson, G.R., 3rd; Denning, D.W.; Fishman, J.A.; Hadley, S.; Herbrecht, R.; Kontoyiannis, D.P.; Marr, K.A.; Morrison, V.A.; Nguyen, M.H.; et al. Practice Guidelines for the Diagnosis and Management of Aspergillosis: 2016 Update by the Infectious Diseases Society of America. Clin. Infect. Dis. 2016, 63, e1-e60. [CrossRef]

10. Cao, C.; Wang, Y.; Husain, S.; Soteropoulos, P.; Xue, C. A mechanosensitive channel governs lipid flippase-mediated echinocandin resistance in Cryptococcus neoformans. mBio 2019, 10, e01952-19. [CrossRef]

11. Grossman, N.T.; Casadevall, A. Physiological differences in Cryptococcus neoformans strains in vitro versus in vivo and their effects on antifungal susceptibility. Antimicrob. Agents Chemother. 2017, 61, e02108-16. [CrossRef] 
12. Salzer, H.J.F.; Schäfer, G.; Hoenigl, M.; Günther, G.; Hoffmann, C.; Kalsdorf, B.; Alanio, A.; Lange, C. Clinical, diagnostic, and treatment disparities between HIV-infected and non-HIV-infected immunocompromised patients with Pneumocystis jirovecii pneumonia. Respiration 2018, 96, 52-65. [CrossRef] [PubMed]

13. Salzer, H.J.F.; Heyckendorf, J.; Kalsdorf, B.; Herzmann, C.; Hoffmann, C.; Lange, C. Chronic cough and severe weight loss in a 55-year-old previously healthy man. Clin. Infect. Dis. 2017, 65, 349-351. [CrossRef] [PubMed]

14. Costa-de-Oliveira, S.; Rodrigues, A.G. Candida albicans antifungal resistance and tolerance in bloodstream infections: The triad yeast-host-antifungal. Microorganisms 2020, 8, 154. [CrossRef] [PubMed]

15. Cowen, L.E.; Sanglard, D.; Howard, S.J.; Rogers, P.D.; Perlin, D.S. Mechanisms of antifungal drug resistance. Cold Spring Harb. Perspect. Med. 2014, 5, a019752. [CrossRef] [PubMed]

16. Romero, M.; Messina, F.; Marin, E.; Arechavala, A.; Depardo, R.; Walker, L.; Negroni, R.; Santiso, G. Antifungal resistance in clinical isolates of Aspergillus spp.: When local epidemiology breaks the norm. J. Fungi 2019, 5, 41. [CrossRef] [PubMed]

17. Lamoth, F.; Lockhart, S.R.; Berkow, E.L.; Calandra, T. Changes in the epidemiological landscape of invasive candidiasis. J. Antimicrob. Chemother. 2018, 73, i4-i13. [CrossRef]

18. Pfaller, M.A.; Diekema, D.J.; Turnidge, J.D.; Castanheira, M.M.; Jones, R.N. Twenty years of the SENTRY antifungal surveillance program: Results for Candida species from 1997-2016. Open Forum Infect. Dis. 2019, 6 (Suppl. 1), S79-S94. [CrossRef]

19. Latgé, J.P.; Chamilos, G. Aspergillus fumigatus and aspergillosis in 2019. Clin. Microbiol. Rev. 2019, 33, e00140-18. [CrossRef]

20. Verweij, P.E.; Zhang, J.; Debets, A.J.M.; Meis, J.F.; van de Veerdonk, F.L.; Schoustra, S.E.; Zwaan, B.J.; Melchers, W.J.G. In-host adaptation and acquired triazole resistance in Aspergillus fumigatus: A dilemma for clinical management. Lancet Infect. Dis. 2016, 16, e251-e260. [CrossRef]

21. Chow, N.A.; Muñoz, J.F.; Gade, L.; Berkow, E.L.; Li, X.; Welsh, R.M.; Forsberg, K.; Lockhart, S.R.; Adam, R.; Alanio, A.; et al. Tracing the evolutionary history and global expansion of Candida auris using population genomic analyses. mBio 2020, 11, e03364-19. [CrossRef] [PubMed]

22. Healey, K.R.; Perlin, D.S. Fungal resistance to echinocandins and the MDR phenomenon in Candida glabrata. J. Fungi 2018, 4, 105.

23. Huang, L.; Crothers, K.; Atzori, C.; Benfield, T.; Miller, R.; Rabodonirina, M.; Helweg-Larsen, J. Dihydropteroate synthase gene mutations in Pneumocystis and sulfa resistance. Emerg. Infect. Dis. 2004,10,1721-1728. [CrossRef] [PubMed]

24. Linder, K.A.; Gandhi, T.N.; Miceli, M.H. Treatment failure of isavuconazole in a patient with cryptococcosis. Mycopathologia 2019, 184, 667-670. [CrossRef] [PubMed]

25. Lamb, D.C.; Corran, A.; Baldwin, B.C.; Kwon-Chung, J.; Kelly, S.L. Resistant P45051A1 activity in azole antifungal tolerant Cryptococcus neoformans from AIDS patients. FEBS Lett. 1995, 368, 326-330. [CrossRef]

26. Perlin, D.S.; Rautemaa-Richardson, R.; Alastruey-Izquerdo, A. The global problem of antifungal resistance: Prevalence, mechanisms, and management. Lancet Infect. Dis. 2017, 17, e383-e392. [CrossRef]

27. Arastehfar, A.; Daneshnia, F.; Salehi, M.; Yaşar, M.; Hoşbul, T.T.; Ilkit, M.; Pan, W.W.; Hagen, F.; Arslan, N.; Türk-Dağı, H.; et al. Low level of antifungal resistance of Candida glabrata blood isolates in Turkey: Fluconazole minimum inhibitory concentration and FKS mutations can predict therapeutic failure. Mycoses 2020, 63, 911-920. [CrossRef] [PubMed]

28. Zhao, Y.; Prideaux, B.; Nagasaki, Y.; Lee, M.H.; Chen, P.Y.; Blanc, L.; Ho, H.; Clancy, C.J.; Nguyen, M.H.; Dartois, V.; et al. Unraveling drug penetration of echinocandin antifungals at the site of infection in an intra-abdominal abscess model. Antimicrob. Agents Chemother. 2017, 61, e01009-17. [CrossRef]

29. Müller, F.M.C.; Seidler, M.; Beauvais, A. Aspergillus fumigatus biofilms in the clinical setting. Med. Mycol. 2011, 49, S96-S100. [CrossRef]

30. Beauvais, A.; Latgé, J.P. Aspergillus biofilm in vitro and in vivo. Microbiol. Spectr. 2015, 3, 3. [CrossRef]

31. Perry, A.M.; Hernday, A.D.; Nobile, C.J. Unraveling how Candida albicans forms sexual biofilms. J. Fungi 2020, 6, 14. [CrossRef] [PubMed]

32. Cavalheiro, M.; Teixeira, M.C. Candida biofilms: Threats, challenges, and promising strategies. Front. Microbiol. 2018, 5, 28. [CrossRef] [PubMed]

33. Araújo, D.; Henriques, M.; Silva, S. Portrait of Candida species biofilm regulatory network genes. Trends Microbiol. 2017, 25, 62-75. [CrossRef] [PubMed] 
34. Guinea, J. Global trends in the distribution of Candida species causing candidemia. Clin. Microbiol. Infect. 2014, 20 (Suppl. 6), 5-10. [CrossRef]

35. Jeffery-Smith, A.; Taori, S.K.; Schelenz, S.; Jeffery, K.; Johnson, E.M.; Borman, A.; Candida auris Incident Management Team; Manuel, R.; Brown, C.S. Candida auris: A review of the literature. Clin. Microbiol. Rev. 2017, 31, e00029-17. [CrossRef]

36. Mathur, P.; Hasan, F.; Singh, P.K.; Malhotra, R.; Walia, K.; Chowdhary, A. Five-year profile of candidaemia at an Indian trauma centre: High rates of Candida auris blood stream infections. Mycoses 2018, 61, 674-680. [CrossRef]

37. Govender, N.P.; Magobo, R.E.; Mpembe, R.; Mhlanga, M.; Matlapeng, P.; Corcoran, C.; Govind, C.; Lowman, W.; Senekal, M.; Thomas, J. Candida auris in South Africa, 2012-2016. Emerg. Infect. Dis. 2018, 24, 2036-2040. [CrossRef]

38. van Schalkwyk, E.; Mpembe, R.S.; Thomas, J.; Shuping, L.; Ismail, H.; Lowman, W.; Karstaedt, A.S.; Chibabhai, V.; Wadula, J.; Avenant, T.; et al. Epidemiologic shift in candidemia driven by Candida auris, South Africa, 2016-2017. Emerg. Infect. Dis. 2019, 25, 1698-1707. [CrossRef]

39. Eyre, D.W.; Sheppard, A.E.; Madder, H.; Moir, I.; Moroney, R.; Quan, T.P.; Griffiths, D.L.; Morgan, M.; Newnham, R.; Sunderland, M.; et al. A Candida auris outbreak and its control in an intensive care setting. N. Engl. J. Med. 2018, 379, 1322-1331. [CrossRef]

40. Theodoropoulos, N.M.; Bolstorff, B.; Bozorgzadeh, A.; Brandeburg, C.; Cumming, M.; Daly, J.S.; Ellison, R.T., 3rd; Forsberg, K.; Gade, L.; Gibson, L.; et al. Candida auris outbreak involving liver transplant recipients in a surgical intensive care unit. Am. J. Transplant. 2020, 20, 3673-3679. [CrossRef]

41. Armstrong, P.A.; Rivera, S.M.; Escandon, P.; Caceres, D.H.; Chow, N.; Stuckey, M.J.; Díaz, J.; Gomez, A.; Vélez, N.; Espinosa-Bode, A.; et al. Hospital-associated multicenter outbreak of emerging fungus Candida auris, Colombia, 2016. Emerg. Infect. Dis. 2019, 25, 1339-1346. [CrossRef] [PubMed]

42. Horton, M.V.; Johnson, C.J.; Kernien, J.F.; Patel, T.D.; Lam, B.C.; Cheong, J.Z.A.; Meudt, J.J.; Shanmuganayagam, D.; Kalan, L.R.; Nett, J.E. Candida auris forms high-burden biofilms in skin niche conditions and on porcine skin. mSphere 2020, 5, e00910-e00919. [CrossRef]

43. Lockhart, S.R.; Iqbal, N.; Cleveland, A.A.; Farley, M.M.; Harrison, L.H.; Bolden, C.B.; Baughman, W.; Stein, B.; Hollick, R.; Park, B.J.; et al. Species identification and antifungal susceptibility testing of Candida bloodstream isolates from population-based surveillance studies in two U.S. cities from 2008 to 2011. J. Clin. Microbiol. 2012, 50, 3435-3442. [CrossRef]

44. Chapman, B.; Slavin, M.; Marriott, D.; Halliday, C.; Kidd, S.; Arthur, I.; Bak, N.; Heath, C.H.; Kennedy, K.; Morrissey, C.O.; et al. Changing epidemiology of candidaemia in Australia. J. Antimicrob. Chemother. 2017, 72, 1103-1108. [CrossRef] [PubMed]

45. Trouvé, C.; Blot, S.; Hayette, M.P.; Jonckheere, S.; Patteet, S.; Rodriguez-Villalobos, H.; Symoens, F.; van Wijngaerden, E.; Lagrou, K. Epidemiology and reporting of candidaemia in Belgium: A multi-centre study. Eur. J. Clin. Microbiol. Infect. Dis. 2017, 36, 649-655. [CrossRef] [PubMed]

46. Astvad, K.M.T.; Johansen, H.K.; Røder, B.L.; Rosenvinge, F.S.; Knudsen, J.D.D.; Lemming, L.; Schønheyder, H.C.; Hare, R.K.; Kristensen, L.; Nielsen, L.; et al. Update from a 12-year nationwide fungaemia surveillance: Increasing intrinsic and acquired resistance causes concern. J. Clin. Microbiol. 2018, 56, e01564-17.

47. Arastehfar, A.; Daneshnia, F.; Hilmioğlu-Polat, S.; Fang, W.; Yaşar, M.; Polat, F.; Metin, D.Y.; Rigole, P.; Coenye, T.; Ilkit, M.; et al. First report of candidemia clonal outbreak caused by emerging fluconazole-resistant Candida parapsilosis isolates harboring Y132F and/or Y132F+K143R in Turkey. Antimicrob. Agents Chemother. 2020, 64, e01001-e01020. [CrossRef]

48. Govender, N.P.; Patel, J.; Magobo, R.E.; Naicker, S.; Wadula, J.; Whitelaw, A.; Coovadia, Y.; Kularatne, R.; Govind, C.; Lockhart, S.R.; et al. Emergence of azole-resistant Candida parapsilosis causing bloodstream infection: Results from laboratory-based sentinel surveillance in South Africa. J. Antimicrob. Chemother. 2016, 71, 1994-2004. [CrossRef]

49. Chen, P.Y.; Chuang, Y.C.; Wu, U.I.; Sun, H.Y.; Wang, J.T.; Sheng, W.H.; Lo, H.J.; Wang, H.Y.; Chen, Y.C.; Chang, S.C. Clonality of fluconazole-nonsusceptible Candida tropicalis in bloodstream infections, Taiwan, 2011-2017. Emerg. Infect. Dis. 2019, 25, 1660-1667. [CrossRef]

50. Lestrade, P.P.A.; Buil, J.B.; van der Beek, M.T.; Kuijper, E.J.; van Dijk, K.; Kampinga, G.A.; Rijnders, B.J.A.; Vonk, A.G.; de Greeff, S.C.; Schoffelen, A.F.; et al. Paradoxal trends in azole-resistant Aspergillus fumigatus in a National Multicenter Surveillance Program, The Netherlands, 2013-2018. Emerg. Infect. Dis. 2020, 26, 1447-1455. [CrossRef] 
51. Espinel-Ingroff, A.; Chowdhary, A.; Cuenca-Estrella, M.; Fothergill, A.; Fuller, J.; Hagen, F.; Govender, N.; Guarro, J.; Johnson, E.; Lass-Flörl, C.; et al. Cryptococcus neoformans-Cryptococcus gattii species complex: An international study of wild-type susceptibility endpoint and epidemiological cutoff values for amphotericin B and flucytosine. Antimicrob. Agents Chemother. 2012, 56, 3107-3113. [CrossRef]

52. Vena, A.; Muñoz, P.; Guinea, J.; Escribano, P.; Peláez, T.; Valerio, M.; Bonache, F.; Gago, S.; Álvarez-Uría, A.; Bouza, E. Fluconazole resistance is not a predictor of poor outcome in patients with cryptococcosis. Mycoses 2019, 62, 441-449. [CrossRef] [PubMed]

53. Lee, C.H.; Chang, T.Y.; Liu, J.W.; Chen, F.J.; Chien, C.C.; Tang, Y.F.; Lu, C.H. Correlation of anti-fungal susceptibility with clinical outcomes in patients with cryptococcal meningitis. BMC Infect. Dis. 2012, 12, 361. [CrossRef] [PubMed]

54. Bongomin, F.; Oladele, R.O.; Gago, S.; Moore, C.B.; Richardson, M.D. A systematic review of fluconazole resistance in clinical isolates of Cryptococcus species. Mycoses 2018, 61, 290-297. [CrossRef] [PubMed]

55. Selb, R.; Fuchs, V.; Graf, B.; Hamprecht, A.; Hogardt, M.; Sedlacek, L.; Schwarz, R.; Idelevich, E.A.; Becker, S.L.; Held, J.; et al. Molecular typing and in vitro resistance of Cryptococcus neoformans clinical isolates obtained in Germany between 2011 and 2017. Int. J. Med. Microbiol. 2019, 309, 151336. [CrossRef] [PubMed]

56. Hagen, F.; Jensen, R.H.; Meis, J.F.; Arendrup, M.C. Molecular epidemiology and in vitro antifungal susceptibility testing of 108 clinical Cryptococcus neoformans sensu lato and Cryptococcus gattii sensu lato isolates from Denmark. Mycoses 2016, 59, 576-584. [CrossRef] [PubMed]

57. Esteves, F.; de Sousa, B.; Calderón, E.J.; Huang, L.; Badura, R.; Maltez, F.; Bassat, Q.; de Armas, Y.; Antunes, F.; Matos, O. Multicentre study highlighting clinical relevance of new high-throughput methodologies in molecular epidemiology of Pneumocystis jirovecii pneumonia. Clin. Microbiol. Infect. 2016, 22, 566.e9-566.e19.

58. Ozkoc, S.; Erguden, C.; Bayram-Delibas, S. Absence of dihydropteroate synthase gene mutations in Pneumocystis jirovecii strains isolated from Aegean region of Turkey. Parasitol. Res. 2018, 117, 3103-3108. [CrossRef]

59. Ponce, C.A.; Chabé, M.; George, C.; Cárdenas, A.; Durán, L.; Guerrero, J.; Bustamante, R.; Matos, O.; Huang, L.; Miller, R.F.; et al. High prevalence of Pneumocystis jirovecii dihydropteroate synthase gene mutations in patients with a first episode of pneumocystis pneumonia in Santiago, Chile, and clinical response to trimethoprim-sulfamethoxazole therapy. Antimicrob. Agents Chemother. 2017, 61, e01290-16. [CrossRef]

60. Suárez, I.; Roderus, L.; van Gumpel, E.; Jung, N.; Lehmann, C.; Fätkenheuer, G.; Hartmann, P.; Plum, G.; Rybniker, J. Low prevalence of DHFR and DHPS mutations in Pneumocystis jirovecii obtained from a German cohort. Infection 2017, 45, 341-347. [CrossRef]

61. Tyagi, A.K.; Mirdha, B.R.; Luthra, K.; Guleria, R.; Mohan, A.; Singh, U.B.; Samantaray, J.C.; Dar, L.; Iyer, V.K.; Chaudhry, R. Dihydropteroate synthase (DHPS) gene mutation study in HIV-infected Indian patients with Pneumocystis jirovecii pneumonia. J. Infect. Dev. Ctries. 2010, 4, 761-766. [CrossRef]

62. Chakrabarti, A.; Sood, P.; Rudramurthy, S.M.; Chen, S.; Kaur, H.; Capoor, M.; Chhina, D.; Rao, R.; Eshwara, V.K.; Xess, I.; et al. Incidence, characteristics and outcome of ICU-acquired candidemia in India. Intensive Care Med. 2015, 41, 285-295. [CrossRef] [PubMed]

63. Hii, I.M.; Chang, H.L.; Lin, L.C.; Lee, Y.L.; Liu, Y.M.; Liu, C.E.; Chen, C.H.; Cheng, Y.R.; Chang, C.Y. Changing epidemiology of candidemia in a medical center in middle Taiwan. J. Microbiol. Immunol. Infect. 2015, 48, 306-315. [CrossRef] [PubMed]

64. Wu, P.F.; Liu, W.L.; Hsieh, M.H.; Hii, I.M.; Lee, Y.L.; Lin, Y.T.; Ho, M.W.; Liu, C.E.; Chen, Y.H.; Wang, F.D. Epidemiology and antifungal susceptibility of candidemia isolates of non-albicans Candida species from cancer patients. Emerg. Microbes Infect. 2017, 6, e87. [CrossRef] [PubMed]

65. Won, E.J.; Shin, J.H.; Choi, M.J.; Lee, W.G.; Park, Y.J.; Uh, Y.; Kim, S.Y.; Lee, M.K.; Kim, S.H.; Shin, M.G.; et al. Antifungal susceptibilities of bloodstream isolates of Candida species from nine hospitals in Korea: Application of new antifungal breakpoints and relationship to antifungal usage. PLoS ONE 2015, 10, e0118770. [CrossRef] [PubMed]

66. Ko, J.H.; Jung, D.S.; Lee, J.Y.; Kim, H.A.; Ryu, S.Y.; Jung, S.I.; Joo, E.J.; Cheon, S.; Kim, Y.S.; Kim, S.W.; et al. Changing epidemiology of non-albicans candidemia in Korea. J. Infect. Chemother. 2019, 25, 388-391. [CrossRef] [PubMed]

67. Guo, F.; Yang, Y.; Kang, Y.; Zang, B.; Cui, W.; Qin, B.; Qin, Y.; Fang, Q.; Qin, T.; Jiang, D.; et al. Invasive candidiasis in intensive care units in China: A multicentre prospective observational study. J. Antimicrob. Chemother. 2013, 68, 1660-1668. [CrossRef]

68. Kakeya, H.; Shibata, W.; Yamada, K.; Kaneko, Y. National trends in the Japanese distribution of major Candida species causing candidemia during 2003-2017: A report by the epidemiological investigation committee for human mycoses in Japan. Open Forum Infect. Dis. 2019, 6 (Suppl. 2), S142. [CrossRef] 
69. Tan, T.Y.; Hsu, L.Y.; Alejandria, M.M.; Chaiwarith, R.; Chinniah, T.; Chayakulkeeree, M.; Choudhury, S.; Chen, Y.H.; Shin, J.H.; Kiratisin, P.; et al. Antifungal susceptibility of invasive Candida bloodstream isolates from the Asia-Pacific region. Med. Mycol. 2016, 54, 471-477. [CrossRef]

70. Khan, Z.; Ahmad, S.; Al-Sweih, N.; Mokaddas, E.; Al-Banwan, K.; Alfouzan, W.; Al-Obaid, I.; Al-Obaid, K.; Asadzadeh, M.; Jeragh, A.; et al. Changing trends in epidemiology and antifungal susceptibility patterns of six bloodstream Candida species isolates over a 12-year period in Kuwait. PLoS ONE 2019, 14, e0216250. [CrossRef]

71. Taj-Aldeen, S.J.; Kolecka, A.; Boesten, R.; Alolaqi, A.; Almaslamani, M.; Chandra, P.; Meis, J.F.; Boekhout, T. Epidemiology of candidemia in Qatar, the Middle East: Performance of MALDI-TOF MS for the identification of Candida species, species distribution, outcome, and susceptibility pattern. Infection 2014, 42, 393-404. [CrossRef]

72. Mirhendi, H.; Charsizadeh, A.; Eshaghi, H.; Nikmanesh, B.; Arendrup, M.C. Species distribution and antifungal susceptibility profile of Candida isolates from blood and other normally sterile foci from pediatric ICU patients in Tehran, Iran. Med. Mycol. 2020, 58, 201-206. [CrossRef] [PubMed]

73. Tortorano, A.M.; Prigitano, A.; Lazzarini, C.; Passera, M.; Deiana, M.L.; Cavinato, S.; De Luca, C.; Grancini, A.; Lo Cascio, G.; Ossi, C.; et al. A 1-year prospective survey of candidemia in Italy and changing epidemiology over one decade. Infection 2013, 41, 655-662. [CrossRef] [PubMed]

74. Puig-Asensio, M.; Padilla, B.; Garnacho-Montero, J.; Zaragoza, O.; Aguado, J.M.; Zaragoza, R.; Montejo, M.; Muñoz, P.; Ruiz-Camps, I.; Cuenca-Estrella, M.; et al. Epidemiology and predictive factors for early and late mortality in Candida bloodstream infections: A population-based surveillance in Spain. Clin. Microbiol. Infect. 2014, 20, O245-O254. [CrossRef] [PubMed]

75. Dimopoulos, G.; Velegraki, A.; Falagas, M.E. A 10-year survey of antifungal susceptibility of candidemia isolates from intensive care unit patients in Greece. Antimicrob. Agents Chemother. 2009, 53, 1242-1244. [CrossRef]

76. Papadimitriou-Olivgeris, M.; Spiliopoulou, A.; Kolonitsiou, F.; Bartzavali, C.; Lambropoulou, A.; Xaplanteri, P.; Anastassiou, E.D.; Marangos, M.; Spiliopoulou, I.; Christofidou, M. Increasing incidence of candidaemia and shifting epidemiology in favor of Candida non-albicans in a 9-year period (2009-2017) in a university Greek hospital. Infection 2019, 47, 209-216. [CrossRef]

77. Leroy, O.; Bailly, S.; Gangneux, J.P.; Mira, J.P.; Devos, P.; Dupont, H.; Montravers, P.; Perrigault, P.F.; Constantin, J.M.; Guillemot, D.; et al. Systemic antifungal therapy for proven or suspected invasive candidiasis: The AmarCAND 2 study. Ann. Intensive Care 2016, 6, 2. [CrossRef]

78. Hesstvedt, L.; Gaustad, P.; Andersen, C.T.; Haarr, E.; Hannula, R.; Haukland, H.H.; Hermansen, N.O.; Larssen, K.W.; Mylvaganam, H.; Ranheim, T.E.; et al. Twenty-two years of candidaemia surveillance: Results from a Norwegian national study. Clin. Microbiol. Infect. 2015, 21, 938-945. [CrossRef]

79. Lindberg, E.; Hammarström, H.; Ataollahy, N.; Kondori, N. Species distribution and antifungal drug susceptibilities of yeasts isolated from the blood samples of patients with candidemia. Sci. Rep. 2019, 9, 12-17. [CrossRef]

80. Poikonen, E.; Lyytikäinen, O.; Anttila, V.J.; Koivula, I.; Lumio, J.; Kotilainen, P.; Syrjälä, H.; Ruutu, P. Secular trend in candidemia and the use of fluconazole in Finland, 2004-2007. BMC Infect. Dis. 2010, 10, 312. [CrossRef]

81. Mari, A.H.; Valkonen, M.; Kolho, E.; Friberg, N.; Anttila, V.J. Clinical and microbiological factors associated with mortality in candidemia in adult patients 2007-2016. Infect. Dis. 2019, 51, 824-830.

82. Sellami, A.; Sellami, H.; Néji, S.; Makni, F.; Abbes, S.; Cheikhrouhou, F.; Chelly, H.; Bouaziz, M.; Hammami, B.; Ben Jemaa, M.; et al. Antifungal susceptibility of bloodstream Candida isolates in Sfax Hospital: Tunisia. Mycopathologia 2011, 171, 417-422. [CrossRef] [PubMed]

83. Megri, Y.; Arastehfar, A.; Boekhout, T.; Daneshnia, F.; Hörtnagl, C.; Sartori, B.; Hafez, A.; Pan, W.; Lass-Flörl, C.; Hamrioui, B. Candida tropicalis is the most prevalent yeast species causing candidemia in Algeria: The urgent need for antifungal stewardship and infection control measures. Antimicrob. Resist. Infect. Control. 2020, 9, 50. [CrossRef] [PubMed]

84. Nucci, M.; Queiroz-Telles, F.; Alvarado-Matute, T.; Tiraboschi, I.N.; Cortes, J.; Zurita, J.; Guzman-Blanco, M.; Santolaya, M.E.; Thompson, L.; Sifuentes-Osornio, J.; et al. Epidemiology of candidemia in Latin America: A laboratory-based survey. PLoS ONE 2013, 8, e59373. [CrossRef] [PubMed]

85. Remington, T.L.; Isaac, A.; Vickers, D.M.; Fuller, J.; Wrenn-Smith, S. Epidemiology of candidemia at a tertiary Canadian hospital, 2004-2013. Can. J. Infect. Dis. Med. Microbiol. 2018, 3, 14-23. [CrossRef] 
86. Arastehfar, A.; Yazdanpanah, S.; Bakhtiari, M.; Fang, W.; Pan, W.; Mahmoudi, S.; Pakshir, K.; Daneshnia, F.; Boekhout, T.; Ilkit, M.; et al. Epidemiology of candidemia in Shiraz, southern Iran: A prospective multicenter study (2016-2018). Med. Mycol. 2020. [CrossRef]

87. Kord, M.; Salehi, M.; Khodavaisy, S.; Hashemi, S.J.; Ghazvini, R.D.; Rezaei, S.; Maleki, A.; Elmimoghaddam, A.; Alijani, N.; Alireza Abdollahi, A.; et al. Epidemiology of yeast species causing bloodstream infection in Tehran, Iran (2015-2017); superiority of 21-plex PCR over the Vitek 2 system for yeast identification. J. Med. Microbiol. 2020, 69, 712-720. [CrossRef]

88. Lockhart, S.R.; Etienne, K.A.; Vallabhaneni, S.; Farooqi, J.; Chowdhary, A.; Govender, N.P.; Colombo, A.L.; Calvo, B.; Cuomo, C.A.; Desjardins, C.A.; et al. Simultaneous emergence of multidrug resistant Candida auris on 3 continents confirmed by whole-genome sequencing and epidemiological analyses. Clin. Infect. Dis. 2017, 64, 134-140. [CrossRef]

89. Vallabhaneni, S.; Kallen, A.; Tsay, S.; Chow, N.; Welsh, R.; Kerins, J.; Kemble, S.K.; Pacilli, M.; Black, S.R.; Landon, E.; et al. Investigation of the first seven reported cases of Candida auris, a globally emerging invasive, multidrug-resistant fungus-United States, May 2013-August 2016. MMWR. Morb. Mortal. Wkly. Rep. 2016, 65, 1234-1237. [CrossRef]

90. Sharma, C.; Kumar, N.; Pandey, R.; Meis, J.F.; Chowdhary, A. Whole genome sequencing of emerging multidrug resistant Candida auris isolates in India demonstrates low genetic variation. New Microbes New Infect. 2016, 13, 77-82. [CrossRef]

91. Chowdhary, A.; Kumar, A.V.; Sharma, C.; Prakash, A.; Agarwal, K.; Babu, R.; Dinesh, K.R.; Karim, S.; Singh, S.K.; Hagen, F.; et al. Multidrug-resistant endemic clonal strain of Candida auris in India. Eur. J. Clin. Microbiol. Infect. Dis. 2014, 33, 919-926. [CrossRef]

92. van der Linden, J.W.M.; Arendrup, M.C.; Warris, A.; Lagrou, K.; Pelloux, H.; Hauser, P.M.; Chryssanthou, E.; Mellado, E.; Kidd, S.E.; Tortorano, A.M.; et al. Prospective multicenter international surveillance of azole resistance in Aspergillus fumigatus. Emerg. Infect. Dis. 2015, 21, 1041-1044. [CrossRef] [PubMed]

93. Lestrade, P.P.A.; Meis, J.F.; Arends, J.P.; van der Beek, M.T.; de Brauwer, E.; van Dijk, K.; de Greeff, S.C.; Haas, P.J.; Hodiamont, C.J.; Kuijper, E.J.; et al. Diagnosis and management of aspergillosis in the Netherlands: A national survey. Mycoses 2016, 59, 101-107. [CrossRef] [PubMed]

94. Rivero-Menendez, O.; Alastruey-Izquierdo, A.; Mellado, E.; Cuenca-Estrella, M. Triazole resistance in Aspergillus spp.: A worldwide problem? J. Fungi 2016, 2, 21. [CrossRef] [PubMed]

95. Garcia-Rubio, R.; Cuenca-Estrella, M.; Mellado, E. Triazole resistance in Aspergillus species: An emerging problem. Drugs 2017, 77, 599-613. [CrossRef] [PubMed]

96. Vermeulen, E.; Maertens, J.; De Bel, A.; Nulens, E.; Boelens, J.; Surmont, I.; Mertens, A.; Boel, A.; Lagrou, K. Nationwide surveillance of azole resistance in Aspergillus diseases. Antimicrob. Agents Chemother. 2015, 59, 4569-4576. [CrossRef]

97. Mortensen, K.L.; Jensen, R.H.; Johansen, H.K.; Skov, M.; Pressler, T.; Howard, S.J.; Leatherbarrow, H.; Mellado, E.; Arendrup, M.C. Aspergillus species and other molds in respiratory samples from patients with cystic fibrosis: A laboratory based study with focus on Aspergillus fumigatus azole resistance. J. Clin. Microbiol. 2011, 49, 2243-2251. [CrossRef] [PubMed]

98. Bakare, N.; Rickerts, V.; Bargon, J.; Just-Nubling, G. Prevalence of Aspergillus fumigatus and other fungal species in the sputum of adult patients with cystic fibrosis. Mycoses 2003, 46, 19-23. [CrossRef]

99. Burgel,P.R.; Baixench, M.T.; Amsellem, M.; Audureau, E.; Chapron, J.; Kanaan, R.; Honoré, I.; Dupouy-Camet, J.; Dusser, D.; Klaassen, C.H.; et al. High prevalence of azole-resistant Aspergillus fumigatus in adults with cystic fibrosis exposed to itraconazole. Antimicrob. Agents Chemother. 2012, 56, 869-874. [CrossRef]

100. Fischer, J.; van Koningsbruggen-Rietschel, S.; Rietschel, E.; Vehreschild, M.J.; Wisplinghoff, H.; Kronke, M.; Hamprecht, A. Prevalence and molecular characterization of azole resistance in Aspergillus spp. isolates from German cystic fibrosis patients. J. Antimicrob. Chemother. 2014, 69, 1533-1536. [CrossRef]

101. Alastruey-Izquierdo, A.; Mellado, E.; Peláez, T.; Pemán, J.; Zapico, S.; Alvarez, M.; Rodríguez-Tudela, J.L.; Cuenca-Estrella, M.; FILPOP Study Group. Population-based survey of filamentous fungi and antifungal resistance in Spain (FILPOP Study). Antimicrob. Agents Chemother. 2013, 57, 3380-3387. [CrossRef]

102. Alastruey-Izquierdo, A.; Alcazar-Fuoli, L.; Rivero-Menéndez, O.; Ayats, J.; Castro, C.; García-Rodríguez, J.; Goterris-Bonet, L.; Ibáñez-Martínez, E.; Linares-Sicilia, M.J.; Martin-Gomez, M.T.; et al. Molecular identification and susceptibility testing of molds isolated in a prospective surveillance of triazole resistance in Spain (FILPOP2 Study). Antimicrob. Agents Chemother. 2018, 62, e00358-18. [CrossRef] [PubMed] 
103. Lamoth, F. Aspergillus fumigatus-related species in clinical practice. Front. Microbiol. 2016, 7, 683. [CrossRef] [PubMed]

104. Falagas, M.E.; Roussos, N.; Vardakas, K.Z. Relative frequency of albicans and the various non-albicans Candida spp. among candidemia isolates from inpatients in various parts of the world: A systematic review. Int. J. Infect. Dis. 2010, 14, e954-e966. [CrossRef]

105. Arendrup, M.C.; Dzajic, E.; Jensen, R.H.; Johansen, H.K.; Kjaeldgaard, P.; Knudsen, J.D.; Kristensen, L.; Leitz, C.; Lemming, L.E.; Nielsen, L.; et al. Epidemiological changes with potential implication for antifungal prescription recommendations for fungaemia: Data from a nationwide fungaemia surveillance programme. Clin. Microbiol. Infect. 2013, 19, e343-e353. [CrossRef] [PubMed]

106. Jensen, R.H.; Hagen, F.; Astvad, K.M.T.; Tyron, A.; Meis, J.F.; Arendrup, M.C. Azole-resistant Aspergillus fumigatus in Denmark: A laboratory-based study on resistance mechanisms and genotypes. Clin. Microbiol. Infect. 2016, 22, e1-e9. [CrossRef] [PubMed]

107. Takeda, K.; Suzuki, J.; Watanabe, A.; Arai, T.; Koiwa, T.; Shinfuku, K.; Narumoto, O.; Kawashima, M.; Fukami, T.; Tamura, A.; et al. High detection rate of azole-resistant Aspergillus fumigatus after treatment with azole antifungal drugs among patients with chronic pulmonary aspergillosis in a single hospital setting with low azole resistance. Med. Mycol. 2020. [CrossRef]

108. Devoto, T.B.; Hermida-Alva, K.; Posse, G.; Finquelievich, J.L.; García-Effrón, G.; Cuestas, M.L. High prevalence of triazole-resistant Aspergillus fumigatus sensu stricto in an Argentinean cohort of patients with cystic fibrosis. Mycoses 2020, 63, 937-941. [CrossRef]

109. Alcazar-Fuoli, L.; Mellado, E.; Alastruey-Izquierdo, A.; Cuenca-Estrella, M.; Rodriguez-Tudela, J.L. Aspergillus section Fumigati: Antifungal susceptibility patterns and sequence-based identification. Antimicrob. Agents Chemother. 2018, 52, 1244-1251. [CrossRef]

110. Whitesell, L.; Robbins, N.; Huang, D.S.; McLellan, C.A.; Shekhar-Guturja, T.; LeBlanc, E.V.; Nation, C.S.; Hui, R.; Hutchinson, A.; Collins, C.; et al. Structural basis for species-selective targeting of Hsp90 in a pathogenic fungus. Nat. Commun. 2019, 10, 402. [CrossRef]

111. Kim, S.H.; Iyer, K.R.; Pardeshi, L.; Muñoz, J.F.; Robbins, N.; Cuomo, C.A.; Wong, K.H.; Cowen, L.E. Genetic analysis of Candida auris implicates Hsp90 in morphogenesis and azole tolerance and Cdr1 in azole resistance. mBio 2019, 10, e02529-18. [CrossRef]

112. Cowen, L.E.; Singh, S.D.; Köhler, J.R.; Collins, C.; Zaas, A.K.; Schell, W.A.; Aziz, H.; Mylonakis, E.; Perfect, J.R.; Whitesell, L.; et al. Harnessing Hsp90 function as a powerful, broadly effective therapeutic strategy for fungal infectious disease. Proc. Natl. Acad. Sci. USA 2009, 106, 2818-2823. [CrossRef] [PubMed]

113. Garzon, A.C.; Amado, D.; Robert, E.; Parra Giraldo, C.M.; Le Pape, P. Impact of calmodulin inhibition by fluphenazine on susceptibility, biofilm formation and pathogenicity of caspofungin-resistant Candida glabrata. J. Antimicrob. Chemother. 2020, 75, 1187-1193. [CrossRef] [PubMed]

114. Caplan, T.; Lorente-Macías, A.; Stogios, P.J.; Evdokimova, E.; Hyde, S.; Wellington, M.A.; Liston, S.; Iyer, K.R.; Puumala, E.; Shekhar-Guturja, T.; et al. Overcoming fungal echinocandin resistance through inhibition of the non-essential stress kinase Yck2. Cell. Chem. Biol. 2020, 27, 269-282. [CrossRef] [PubMed]

115. Rosenberg, A.; Ene, I.V.; Bibi, M.; Zakin, S.; Segal, E.S.; Ziv, N.; Dahan, A.M.; Colombo, A.L.; Bennett, R.J.; Berman, J. Antifungal tolerance is a subpopulation effect distinct from resistance and is associated with persistent candidemia. Nat. Commun. 2018, 9, 2470. [CrossRef] [PubMed]

116. Astvad, K.M.T.; Sanglard, D.; Delarze, E.; Hare, R.K.; Arendrup, M.C. Implications of the EUCAST trailing phenomenon in Candida tropicalis for the in vivo susceptibility in invertebrate and murine models. Antimicrob. Agents Chemother. 2018, 62, e01624-18. [CrossRef] [PubMed]

117. Healey, K.R.; Jiménez-Ortigosa, C.; Shor, E.; Perlin, D.S. Genetic drivers of multidrug resistance in Candida glabrata. Front. Microbiol. 2016, 7, 1995. [CrossRef]

118. Arastehfar, A.; Hilmioğlu-Polat, S.; Daneshnia, F.; Hafez, A.; Salehi, M.; Polat, F.; Yaşar, M.; Arslan, N.; Hoşbul, T.; Ünal, N.; et al. Recent increase in the prevalence of fluconazole-non-susceptible Candida tropicalis blood isolates in Turkey: Clinical implication of azole-non-susceptible and fluconazole tolerant phenotypes and genotyping. Front. Microbiol. 2020, 11, 587278. [CrossRef]

119. Gerstein, A.C.; Berman, J. Candida albicans genetic background influences mean and heterogeneity of drug responses and genome stability during evolution in fluconazole. mSphere 2020, 5, e00480-20. [CrossRef] 
120. Schmidt, F.; Thywißen, A.; Goldmann, M.; Cunha, C.; Cseresnyés, Z.; Schmidt, H.; Rafiq, M.; Galiani, S.; Gräler, M.H.; Chamilos, G.; et al. Flotillin-dependent membrane microdomains are required for functional phagolysosomes against fungal infections. Cell. Rep. 2020, 32, 108017. [CrossRef]

121. Arastehfar, A.; Daneshnia, F.; Zomorodian, K.; Najafzadeh, M.J.; Khodavaisy, S.; Zarrinfar, H.; Hagen, F.; Shahrabadi, Z.Z.; Lackner, M.; Mirhendi, H.; et al. Low level of antifungal resistance in Iranian isolates of Candida glabrata recovered from blood samples in a multicenter study from 2015 to 2018 and potential prognostic values of genotyping and sequencing of PDR1. Antimicrob. Agents Chemother. 2019, 63, e02503-18. [CrossRef]

122. Arastehfar, A.; Daneshnia, F.; Najafzadeh, M.J.; Hagen, F.; Mahmoudi, S.; Salehi, M.; Zarrinfar, H.; Namvar, Z.; Shahrabadi, Z.Z.; Khodavaisy, S.; et al. Evaluation of molecular epidemiology, clinical characteristics, antifungal susceptibility profiles, and molecular mechanisms of antifungal resistance of Iranian Candida parapsilosis species complex blood isolates. Front. Cell. Infect. Microbiol. 2020, 10, 206. [CrossRef] [PubMed]

123. Arastehfar, A.; Wickes, B.L.; Ilkit, M.; Pincus, D.H.; Daneshnia, F.; Pan, W.; Fang, W.; Boekhout, T. Identification of mycoses in developing countries. J. Fungi 2019, 5, 90. [CrossRef] [PubMed]

124. Nishimoto, A.T.; Sharma, C.; Rogers, P.D. Molecular and genetic basis of azole antifungal resistance in the opportunistic pathogenic fungus Candida albicans. J. Antimicrob. Chemother. 2020, 75, 257-270. [CrossRef] [PubMed]

125. Healey, K.R.; Kordalewska, M.; Jiménez-Ortigosa, C.; Singh, A.; Berrío, I.; Chowdhary, A.; Perlin, D.S. Limited ERG11 mutations identified in isolates of Candida auris directly contribute to reduced azole susceptibility. Antimicrob. Agents Chemother. 2018, 62, e01427-18. [CrossRef] [PubMed]

126. Fan, X.; Xiao, M.; Zhang, D.; Huang, J.J.; Wang, H.; Hou, X.; Zhang, L.; Kong, F.; Chen, S.C.A.; Tong, Z.H.; et al. Molecular mechanisms of azole resistance in Candida tropicalis isolates causing invasive candidiasis in China. Clin. Microbiol. Infect. 2019, 25, 885-891. [CrossRef]

127. Yao, D.; Chen, J.; Chen, W.; Li, Z.; Hu, X. Mechanisms of azole resistance in clinical isolates of Candida glabrata from two hospitals in China. Infect. Drug Resist. 2019, 12, 771-781. [CrossRef]

128. Branco, J.; Ola, M.; Silva, R.M.; Fonseca, E.; Gomes, N.C.; Martins-Cruz, C.; Silva, A.P.; Silva-Dias, A.; Pina-Vaz, C.; Erraught, C.; et al. Impact of ERG3 mutations and expression of ergosterol genes controlled by UPC2 and NDT80 in Candida parapsilosis azole resistance. Clin. Microbiol. Infect. 2017, 23, 575.e1-575.e8. [CrossRef]

129. Yang, H.; Tong, J.; Lee, C.W.; Ha, S.; Eom, S.H.; Im, Y.J. Structural mechanism of ergosterol regulation by fungal sterol transcription factor Upc2. Nat. Commun. 2015, 6, 6129. [CrossRef]

130. Vu, B.G.; Thomas, G.H.; Moye-Rowley, W.S. Evidence that ergosterol biosynthesis modulates activity of the Pdr1 transcription factor in Candida glabrata. mBio 2019, 10, e00934-19. [CrossRef]

131. Pais, P.; Califórnia, R.; Galocha, M.; Viana, R.; Ola, M.; Cavalheiro, M.; Takahashi-Nakaguchi, A.; Chibana, H.; Butler, G.; Teixeira, M.C. Candida glabrata transcription factor Rpn4 mediates fluconazole resistance through regulation of ergosterol biosynthesis and plasma membrane permeability. Antimicrob. Agents Chemother. 2020, 64, e00554-20. [CrossRef]

132. Perlin, D.S.; Shor, E.; Zhao, Y. Update on antifungal drug resistance. Curr. Clin. Microbiol. Rep. 2015, 2, 84-95. [CrossRef] [PubMed]

133. Arastehfar, A.; Lass-Flörl, C.; Garcia-Rubio, R.; Daneshnia, F.; Ilkit, M.; Boekhout, T.; Gabaldón, T.; Perlin, D.S. The quiet and underappreciated rise of drug-resistant invasive fungal pathogens. J. Fungi 2020, 6, 138. [CrossRef] [PubMed]

134. Arastehfar, A.; Daneshnia, F.; Hafez, A.; Khodavaisy, S.; Najafzadeh, M.J.; Charsizadeh, A.; Zarrinfar, H.; Salehi, M.; Shahrabadi, Z.Z.; Sasani, E.; et al. Antifungal susceptibility, genotyping, resistance mechanism, and clinical profile of Candida tropicalis blood isolates. Med. Mycol. 2020, 58, 766-773. [CrossRef] [PubMed]

135. Grossman, N.T.; Pham, C.D.; Cleveland, A.A.; Lockhart, S.R. Molecular mechanisms of fluconazole resistance in Candida parapsilosis isolates from a U.S. surveillance system. Antimicrob. Agents Chemother. 2015, 59, 1030-1037. [CrossRef]

136. Choi, Y.J.; Kim, Y.J.; Yong, D.; Byun, J.H.; Kim, T.S.; Chang, Y.S.; Choi, M.J.; Byeon, S.A.; Won, E.J.; Kim, S.H.; et al. Fluconazole-resistant Candida parapsilosis bloodstream isolates with Y132F mutation in ERG11 gene, South Korea. Emerg. Infect. Dis. 2018, 24, 1768-1770. [CrossRef]

137. Rybak, J.M.; Muñoz, J.M.; Barker, K.S.; Parker, J.E.; Esquivel, B.D.; Berkow, E.L.; Lockhart, S.R.; Gade, L.; Palmer, G.E.; White, T.C. Mutations in TAC1B: A novel genetic determinant of clinical fluconazole resistance in Candida auris. mBio 2020, 11, e00365-20. [CrossRef]

138. Hou, X.; Xiao, M.; Wang, H.; Yu, S.Y.; Zhang, G.; Zhao, Y.; Xu, Y.C. Profiling of PDR1 and MSH2 in Candida glabrata bloodstream isolates from a multicenter study in China. Antimicrob. Agents Chemother. 2018, 62, e00153-18. [CrossRef] 
139. Cavalheiro, M.; Costa, C.; Silva-Dias, A.; Miranda, I.M.; Wang, C.; Pais, P.; Pinto, S.N.; Mil-Homens, D.; Sato-Okamoto, M.; Takahashi-Nakaguchi, A.; et al. A transcriptomics approach to unveiling the mechanisms of in vitro evolution towards fluconazole resistance of a Candida glabrata clinical isolate. Antimicrob. Agents Chemother. 2018, 63, e00995-18. [CrossRef]

140. Vale-Silva, L.; Ischer, F.; Leibundgut-Landmann, S.; Sanglard, D. Gain-of-function mutations in PDR1, a regulator of antifungal drug resistance in Candida glabrata, control adherence to host cells. Infect. Immun 2013, 81, 1709-1720. [CrossRef]

141. Ferrari, S.; Ischer, F.; Calabrese, D.; Posteraro, B.; Sanguinetti, M.; Fadda, G.; Rohde, B.; Bauser, C.; Bader, O.; Sanglard, D. Gain of function mutations in CgPDR1 of Candida glabrata not only mediate antifungal resistance but also enhance virulence. PLoS Pathog. 2009, 5, e1000268. [CrossRef]

142. Dudakova, A.; Spiess, B.; Tangwattanachuleeporn, M.; Sasse, C.; Buchheidt, D.; Weig, M.; Gro $\beta$, U.; Bader, O. Molecular tools for the detection and deduction of azole antifungal drug resistance phenotypes in Aspergillus species. Clin. Microbiol. Rev. 2017, 30, 1065-1091. [CrossRef]

143. Willger, S.D.; Puttikamonkul, S.; Kim, K.H.; Burritt, J.B.; Grahl, N.; Metzler, L.J.; Barbuch, R.; Bard, M.; Lawrence, C.B.; Cramer, R.A., Jr. A sterol-regulatory element binding protein is required for cell polarity, hypoxia adaptation, azole drug resistance, and virulence in Aspergillus fumigatus. PLoS Pathog. 2008, 4, e1000200. [CrossRef]

144. Hagiwara, D.; Miura, D.; Shimizu, K.; Paul, S.; Ohba, A.; Gonoi, T.; Watanabe, A.; Kamei, K.; Shintani, T.; Moye-Rowley, W.S.; et al. A novel Zn2-Cys6 transcription factor AtrR plays a key role in an azole resistance mechanism of Aspergillus fumigatus by co-regulating cyp51A and cdr1B expressions. PLoS Pathog. 2017, 13, e1006096. [CrossRef]

145. Gsaller, F.; Hortschansky, P.; Furukawa, T.; Carr, P.D.; Rash, B.; Capilla, J.; Müller, C.; Bracher, F.; Bowyer, P.; Haas, H.; et al. Sterol biosynthesis and azole tolerance is governed by the opposing actions of SrbA and the CCAAT binding complex. PLoS Pathog. 2016, 12, e1005775.

146. Camps, S.M.T.; Dutilh, B.E.; Arendrup, M.C.; Rijs, A.J.M.M.; Snelders, E.; Huynen, M.A.; Verweij, P.E.; Melchers, W.J.G. Discovery of a HapE mutation that causes azole resistance in Aspergillus fumigatus through whole genome sequencing and sexual crossing. PLoS ONE 2012, 7, e50034. [CrossRef] [PubMed]

147. Ukai, Y.; Kuroiwa, M.; Kurihara, N.; Naruse, H.; Homma, T.; Maki, H.; Naito, A. Contributions of yap1 mutation and subsequent atrF upregulation to voriconazole resistance in Aspergillus flavus. Antimicrob. Agents Chemother. 2018, 62, e01216-18. [CrossRef]

148. dos Reis, T.F.; Pereira Silva, L.; Alves de Castro, P.; do Carmo, R.A.; Mendes Marini, M.; da Silveira, J.F.; Ferreira, B.H.; Rodrigues, F.; Lind, A.L.; Rokas, A.; et al. The Aspergillus fumigatus mismatch repair MSH2 homolog is important for virulence and azole resistance. $m$ Sphere 2019, 4, e00416-e00419. [CrossRef] [PubMed]

149. Rybak, J.M.; Ge, W.; Wiederhold, N.P.; Parker, J.E.; Kelly, S.L.; Rogers, P.D.; Fortwendel, J.R. Mutations in $h m g 1$, challenging the paradigm of clinical triazole resistance in Aspergillus fumigatus. mBio 2019, 10, e00437-19. [CrossRef]

150. Song, J.; Zhai, P.; Zhang, Y.; Zhang, C.; Sang, H.; Han, G.; Keller, N.P.; Lu, L. The Aspergillus fumigatus damage resistance protein family coordinately regulates ergosterol biosynthesis and azole susceptibility. mBio 2016, 7, e01919-15. [CrossRef] [PubMed]

151. Furukawa, T.; van Rhijn, N.; Fraczek, M.; Gsaller, F.; Davies, E.; Carr, P.; Gago, S.; Fortune-Grant, R.; Rahman, S.; Gilsenan, J.M.; et al. The negative cofactor 2 complex is a key regulator of drug resistance in Aspergillus fumigatus. Nat. Commun. 2020, 11, 427. [CrossRef]

152. Arendrup, M.C.; Perlin, D.S. Echinocandin resistance: An emerging clinical problem? Curr. Opin. Infect. Dis. 2014, 27, 484-492. [CrossRef] [PubMed]

153. Jiménez-Ortigosa, C.; Moore, C.; Denning, D.W.; Perlin, D.S. Emergence of echinocandin resistance due to a point mutation in the $f k s 1$ gene of Aspergillus fumigatus in a patient with chronic pulmonary aspergillosis. Antimicrob. Agents Chemother. 2017, 61, e01277-17. [CrossRef] [PubMed]

154. Pham, C.D.; Iqbal, N.; Bolden, C.B.; Kuykendall, R.J.; Harrison, L.H.; Farley, M.M.; Schaffner, W.; Beldavs, Z.G.; Chiller, T.M.; Park, B.J.; et al. Role of FKS mutations in Candida glabrata: MIC values, echinocandin resistance, and multidrug resistance. Antimicrob. Agents Chemother. 2014, 58, 4690-4696. [CrossRef] [PubMed]

155. Perlin, D.S. Resistance to echinocandin-class antifungal drugs. Drug Resist. Updat. 2007, 10, 121-130. [CrossRef]

156. García-Effrón, G.; Katiyar, S.K.; Park, S.; Edlind, T.D.; Perlin, D.S. A naturally occurring proline-to-alanine amino acid change in Fks1p in Candida parapsilosis, Candida orthopsilosis, and Candida metapsilosis accounts for reduced echinocandin susceptibility. Antimicrob. Agents Chemother. 2008, 52, 2305-2312. [CrossRef] 
157. Arastehfar, A.; Daneshnia, F.; Hilmioğlu-Polat, S.; Ilkit, M.; Yaşar, M.; Polat, F.; Metin, D.Y.; Dökümcü, Ü.Z.; Pan, W.; Hagen, F.; et al. Genetically-related micafungin-resistant C. parapsilosis blood isolates harboring a novel mutation R658G in hotspot1-Fks1p: A new challenge? J. Antimicrob. Chemother. 2020. [CrossRef]

158. Verweij, P.E.; Ananda-Rajah, M.; Andes, D.; Arendrup, M.C.; Brüggemann, R.J.; Chowdhary, A.; Cornely, O.A.; Denning, D.W.; Groll, A.H.; Izumikawa, K.; et al. International expert opinion on the management of infection caused by azole-resistant Aspergillus fumigatus. Drug Resist. Updat. 2015, 21-22, 30-40. [CrossRef]

159. Satish, S.; Jiménez-Ortigosa, C.; Zhao, Y.; Lee, M.H.; Dolgov, E.; Krüger, T.; Park, S.; Denning, D.W.; Kniemeyer, O.; Brakhage, A.A.; et al. Stress-induced changes in the lipid microenvironment of $\beta$-(1,3)-D-glucan synthase cause clinically important echinocandin resistance in Aspergillus fumigatus. mBio 2019, 10, e00779-19. [CrossRef]

160. Hou, X.; Healey, K.R.; Shor, E.; Kordalewska, M.; Jiménez-Ortigosa, C.; Paderu, P.; Xiao, M.; Wang, H.; Zhao, Y.; Lin, L.Y.; et al. Novel FKS1 and FKS2 modifications in a high-level echinocandin resistant clinical isolate of Candida glabrata. Emerg. Microbes Infect. 2019, 8, 1619-1625. [CrossRef]

161. Kano, R.; Okubo, M.; Hasegawa, A.; Kamata, H. Multi-azole-resistant strains of Cryptococcus neoformans var. grubii isolated from a FLZ-resistant strain by culturing in medium containing voriconazole. Med. Mycol. 2017, 55, 877-882.

162. Kano, R.; Sugita, T.; Kamata, H. Antifungal susceptibility of clinical isolates and artificially produced multi-azole-resistant strains of Cryptococcus neoformans (formaly: Cryptococcus grubii) to ravuconazole. Med. Mycol. J. 2020, 61, 11-13. [CrossRef] [PubMed]

163. Mondon, P.; Petter, R.; Amalfitano, G.; Luzzati, R.; Concia, E.; Polacheck, I.; Kwon-Chung, K.J. Heteroresistance to fluconazole and voriconazole in Cryptococcus neoformans. Antimicrob. Agents Chemother. 1999, 43, 1856-1861. [CrossRef] [PubMed]

164. Sionov, E.; Chang, Y.C.; Kwon-Chung, K.J. Azole heteroresistance in Cryptococcus neoformans: Emergence of resistant clones with chromosomal disomy in the mouse brain during fluconazole treatment. Antimicrob. Agents Chemother. 2013, 57, 5127-5130. [CrossRef] [PubMed]

165. Hope, W.; Stone, N.R.H.; Johnson, A.; McEntee, L.; Farrington, N.; Santoro-Castelazo, A.; Liu, X.; Lucaci, A.; Hughes, M.; Oliver, J.D.; et al. Fluconazole monotherapy is a suboptimal option for initial treatment of cryptococcal meningitis because of emergence of resistance. mBio 2019, 10, e02575-19. [CrossRef] [PubMed]

166. Billmyre, R.B.; Applen-Clancey, S.; Li, L.X.; Doering, T.L.; Heitman, J. 5-fluorocytosine resistance is associated with hypermutation and alterations in capsule biosynthesis in Cryptococcus. Nat. Commun. 2020, 11, 127. [CrossRef] [PubMed]

167. Stone, N.R.H.; Rhodes, J.; Fisher, M.C.; Mfinanga, S.; Kivuyo, S.; Rugemalila, J.; Segal, E.S.; Needleman, L.; Molloy, S.F.; Kwon-Chung, J.; et al. Dynamic ploidy changes drive fluconazole resistance in human cryptococcal meningitis. J. Clin. Investig. 2019, 129, 999-1014. [CrossRef] [PubMed]

168. Maligie, M.A.; Selitrennikoff, C.P. Cryptococcus neoformans resistance to echinocandins: $(1,3)$ beta-glucan synthase activity is sensitive to echinocandins. Antimicrob. Agents Chemother. 2005, 49, 2851-2856. [CrossRef]

169. van Duin, D.; Casadevall, A.; Nosanchuk, J.D. Melanization of Cryptococcus neoformans and Histoplasma capsulatum reduces their susceptibilities to amphotericin B and caspofungin. Antimicrob. Agents Chemother. 2002, 46, 3394-3400. [CrossRef]

170. Kaneshiro, E.S. Sterol metabolism in the opportunistic pathogen Pneumocystis: Advances and new insights. Lipids 2004, 39, 753-761. [CrossRef]

171. Porollo, A.; Meller, J.; Joshi, Y.; Jaiswal, V.; Smulian, A.G.; Cushion, M.T. Analysis of current antifungal agents and their targets within the Pneumocystis carinii genome. Curr. Drug Targets 2012, 13, 1575-1585. [CrossRef]

172. Volpe, F.; Dyer, M.; Scaife, J.G.; Darby, G.; Stammers, D.K.; Delves, C.J. The multifunctional folic acid synthesis fas gene of Pneumocystis carinii appears to encode dihydropteroate synthase and hydroxymethyldihydropterin pyrophosphokinase. Gene 1992, 112, 213-218. [CrossRef]

173. Ma, L.; Borio, L.; Masur, H.; Kovacs, J.A. Pneumocystis carinii dihydropteroate synthase but not dihydrofolate reductase gene mutations correlate with prior trimethoprim-sulfamethoxazole or dapsone use. J. Infect. Dis. 1999, 180, 1969-1978. [CrossRef] [PubMed]

174. Stein, C.R.; Poole, C.; Kazanjian, P.; Meshnick, S.R. Sulfa use, dihydropteroate synthase mutation, and Pneumocystis jirovecii pneumonia. Emerg. Infect. Dis. 2004, 10, 1760-1765. [CrossRef] [PubMed] 
175. Singh, Y.; Mirdha, B.R.; Guleria, R.; Kabra, S.K.; Mohan, A.; Chaudhry, R.; Kumar, L.; Dwivedi, S.N.; Agarwal, S.K. Novel dihydropteroate synthase gene mutation in Pneumocystis jirovecii among HIV-infected patients in India: Putative association with drug resistance and mortality. J. Glob. Antimicrob. Resist. 2019, 17, 236-239. [CrossRef] [PubMed]

176. Crothers, K.; Beard, C.B.; Turner, J.; Groner, G.; Fox, M.; Morris, A.; Eiser, S.; Huang, L. Severity and outcome of HIV-associated Pneumocystis pneumonia containing Pneumocystis jirovecii dihydropteroate synthase gene mutaion. AIDS 2005, 19, 801-805. [CrossRef] [PubMed]

177. Singh, Y.; Mirdha, B.R.; Guleria, R.; Kabra, S.K.; Mohan, A.; Chaudhry, R.; Kumar, L.; Dwivedi, S.N.; Agarwal, S.K. Genetic polymorphisms associated with treatment failure and mortality in pediatric pneumocystosis. Sci. Rep. 2019, 9, 1192. [CrossRef]

178. Knabl, L.; Lass-Flörl, C. Antifungal susceptibility testing in Candida species: Current methods and promising new tools for shortening the turnaround time. Expert Rev. Anti Infect. Ther. 2020, 18, 779-787. [CrossRef]

179. Arendrup, M.C.; Cuenca-Estrella, M.; Lass-Flörl, C.; Hope, W.; EUCAST-AFST Collaborators. EUCAST technical note on the EUCAST definitive document EDef 7.2: Method for the determination of broth dilution minimum inhibitory concentrations of antifungal agents for yeasts EDef 7.2 (EUCAST-AFST). Clin. Microbiol. Infect. 2012, 18, E246-E247. [CrossRef]

180. Eggimann, P.; Que, Y.A.; Revelly, J.P.; Pagani, J.L. Preventing invasive Candida infections. Where could we do better? J. Hosp. Infect. 2015, 89, 302-308. [CrossRef]

181. Berkow, E.L.; Lockhart, S.R.; Ostrosky-Zeichner, L. Antifungal susceptibility testing: Current approaches. Clin. Microbiol. Rev. 2020, 33, e00069-19. [CrossRef]

182. Arendrup, M.C.; Meletiadis, J.; Mouton, J.W.; Guinea, J.; Cuenca-Estrella, M.; Lagrou, K.; Howard, S.J. Subcommittee on Antifungal Susceptibility Testing (AFST) of the ESCMID European Committee for Antimicrobial Susceptibility Testing (EUCAST). EUCAST technical note on isavuconazole breakpoints for Aspergillus, itraconazole breakpoints for Candida and updates for the antifungal susceptibility testing method documents. Clin. Microbiol. Infect. 2016, 22, 571.e1-571.e4.

183. Clinical and Laboratory Standards Institute. M27-A3: Reference Method for Broth Microdilution Antifungal Susceptibility Testing for Yeasts; CLSI: Wayne, PA, USA, 2019.

184. Clinical and Laboratory Standards Institute. M38-A2: Reference Method for Broth Microdilution Antifungal Susceptibility Testing of Filamenteous Fungi; CLSI: Wayne, PA, USA, 2019.

185. Meletiadis, J.; Siopi, M.; Kanioura, L.; Jørgensen, K.M.; Perlin, D.S.; Mouton, J.W.; Arendrup, M.C. Development and multicentre validation of an agar-based screening method for echinocandin susceptibility testing of Aspergillus species. J. Antimicrob. Chemother. 2019, 74, 2247-2254. [CrossRef] [PubMed]

186. Delma, F.Z.; Al-Hatmi, A.M.S.; Buil, J.B.; van der Lee, H.; Tehupeiory-Kooreman, M.; de Hoog, G.S.; Meletiadis, J.; Verweij, P.E. Comparison of MIC Test Strip and Sensititre YeastOne with the CLSI and EUCAST broth microdilution reference methods for in vitro antifungal susceptibility testing of Cryptococcus neoformans. Antimicrob. Agents Chemother. 2020, 64, e02261-19. [CrossRef]

187. Bassetti, M.; Vena, A.; Bouza, E.; Peghin, M.; Muñoz, P.; Righi, E.; Pea, F.; Lackner, M.; Lass-Flörl, C. Antifungal susceptibility testing in Candida, Aspergillus and Cryptococcus infections: Are the MICs useful for clinicians? Clin. Microbiol. Infect. 2020, 26, 1024-1033. [CrossRef] [PubMed]

188. Vatanshenassan, M.; Boekhout, T.; Lass-Flörl, C.; Lackner, M.; Schubert, S.; Kostrzewa, M.; Sparbier, K. Proof of concept for MBT ASTRA, a rapid matrix-assisted laser desorption ionization-time of flight mass spectrometry (MALDI-TOF MS)-based method to detect caspofungin resistance in Candida albicans and Candida glabrata. J. Clin. Microbiol. 2018, 56, e00420-18. [CrossRef] [PubMed]

189. Vatanshenassan, M.; Arastehfar, A.; Boekhout, T.; Berman, J.; Lass-Flörl, C.; Sparbier, K.; Kostrzewa, M. Anidulafungin susceptibility testing of Candida glabrata isolates from blood cultures by the MALDI Biotyper Antibiotic (Antifungal) susceptibility test rapid assay. Antimicrob. Agents Chemother. 2019, 63, e00554-19. [CrossRef] [PubMed]

190. Ksiezopolska, E.; Gabaldón, T. Evolutionary emergence of drug resistance in Candida opportunistic pathogens. Genes 2018, 9, 461. [CrossRef]

191. Consortium, O.; Gabaldón, T. Recent trends in molecular diagnostics of yeast infections: From PCR to NGS. FEMS Microbiol. Rev. 2019, 43, 517-547. [CrossRef]

192. Greninger, A.L. The challenge of diagnostic metagenomics. Expert Rev. Mol. Diagn. 2018, 18, 605-615. [CrossRef] 
193. Kidd, S.E.; Chen, S.C.A.; Meyer, W.; Halliday, C.L. A new age in molecular diagnostics for invasive fungal disease: Are we ready? Front. Microbiol. 2020, 10, 2903. [CrossRef]

194. Perlin, D.S.; Wiederhold, N.P. Culture-independent molecular methods for detection of antifungal resistance mechanisms and fungal identification. J. Infect. Dis. 2017, 216, S458-S465. [CrossRef] [PubMed]

195. Frade, J.P.; Warnock, D.W.; Arthington-Skaggs, B.A. Rapid quantification of drug resistance gene expression in Candida albicans by reverse transcriptase LightCycler PCR and fluorescent probe hybridization. J. Clin. Microbiol. 2004, 42, 2085-2093. [CrossRef] [PubMed]

196. Tsai, H.F.; Sammons, L.R.; Zhang, X.; Suffis, S.D.; Su, Q.; Myers, T.G.; Marr, K.A.; Bennett, J.E. Microarray and molecular analyses of the azole resistance mechanism in Candida glabrata oropharyngeal isolates. Antimicrob. Agents Chemother. 2010, 54, 3308-3317. [CrossRef] [PubMed]

197. Sharma, C.; Nelson-Sathi, S.; Singh, A.; Radhakrishna Pillai, M.; Chowdhary, A. Genomic perspective of triazole resistance in clinical and environmental Aspergillus fumigatus isolates without cyp51A mutations. Fungal Genet. Biol. 2019, 132, 103265. [CrossRef] [PubMed]

198. De Backer, M.D.; Ilyina, T.; Ma, X.J.; Vandoninck, S.; Luyten, W.H.; Vanden Bossche, H. Genomic profiling of the response of Candida albicans to itraconazole treatment using a DNA microarray. Antimicrob. Agents Chemother. 2001, 45, 1660-1670. [CrossRef] [PubMed]

199. Montesinos, I.; Delforge, M.L.; Ajjaham, F.; Brancart, F.; Hites, M.; Jacobs, F.; Denis, O. Evaluation of a new commercial real-time PCR assay for diagnosis of Pneumocystis jirovecii pneumonia and identification of dihydropteroate synthase (DHPS) mutations. Diagn. Microbiol. Infect. Dis. 2017, 87, 32-36. [CrossRef]

200. Stoesser, N.; Batty, E.M.; Eyre, D.W.; Morgan, M.; Wyllie, D.H.; Del Ojo, C.E.; Johnson, J.R.; Walker, A.S.; Peto, T.E.A.; Crook, D.W. Predicting antimicrobial susceptibilities for Escherichia coli and Klebsiella pneumoniae isolates using whole genomic sequence data. J. Antimicrob. Chemother. 2013, 68, 2234-2244. [CrossRef]

201. Ferreira, I.; Beisken, S.; Lueftinger, L.; Weinmaier, T.; Klein, M.; Bacher, J.; Patel, R.; Arndt von Haeseler, A.; Posch, A.E. Species identification and antibiotic resistance prediction by analysis of whole-genome sequence data by use of ARESdb: An analysis of isolates from the unyvero lower respiratory tract infection trial. J. Clin. Microbiol. 2020, 58, e00273-20. [CrossRef]

202. Gupta, C.L.; Tiwari, R.K.; Cytryn, E. Platforms for elucidating antibiotic resistance in single genomes and complex metagenomes. Environ. Int. 2020, 138, 105667. [CrossRef]

203. Graf, E.H.; Pancholi, P. Appropriate use and future directions of molecular diagnostic testing. Curr. Infect. Dis. Rep. 2020, 22, 5. [CrossRef]

204. Chiu, C.Y.; Miller, S.A. Clinical metagenomics. Nat. Rev. Genet. 2019, 20, 341-355. [CrossRef]

205. Rice, J.P.; Seifert, M.; Moser, K.S.; Rodwell, T.C. Performance of the Xpert MTB/RIF assay for the diagnosis of pulmonary tuberculosis and rifampin resistance in a low-incidence, high-resource setting. PLoS ONE 2017, 12, e0186139. [CrossRef]

206. Ullmann, A.J.; Aguado, J.M.; Arikan-Akdagli, S.; Denning, D.W.; Groll, A.H.; Lagrou, K.; Lass-Flörl, C.; Lewis, R.E.; Munoz, P.; Verweij, P.E.; et al. Diagnosis and management of Aspergillus diseases: Executive summary of the 2017 ESCMID-ECMM-ERS guideline. Clin. Microbiol. Infect. 2018, 24 (Suppl. 1), e1-e38. [CrossRef]

207. Tissot, F.; Agrawal, S.; Pagano, L.; Petrikkos, G.; Groll, A.H.; Skiada, A.; Lass-Flörl, C.; Calandra, T.; Viscoli, C.; Herbrecht, R. ECIL-6 guidelines for the treatment of invasive candidiasis, aspergillosis and mucormycosis in leukemia and hematopoietic stem cell transplant patients. Hematologica 2017, 102, 433-444. [CrossRef] [PubMed]

208. Denning, D.W.; Cadranel, J.; Beigelman-Aubry, C.; Ader, F.; Chakrabarti, A.; Blot, S.; Ullmann, A.J.; Dimopoulos, G.; Lange, C.; European Society for Clinical Microbiology and Infectious Diseases and European Respiratory Society. Chronic pulmonary aspergillosis: Rationale and clinical guidelines for diagnosis and management. Eur. Respir. J. 2016, 47, 45-68. [CrossRef]

209. Cuenca-Estrella, M.; Verweij, P.E.; Arendrup, M.C.; Arikan-Akdagli, S.; Bille, J.; Donnelly, J.P.; Jensen, E.H.; Lass-Flörl, C.; Richardson, M.D.; Akova, M.; et al. ESCMID* guideline for the diagnosis and management of Candida diseases 2012: Diagnostic procedures. Clin. Microbiol. Infect. 2012, 18 (Suppl. 7), 9-18. [CrossRef] [PubMed]

210. Andes, D.; Marchillo, K.; Conklin, R.; Krishna, G.; Ezzet, F.; Cacciapuoti, A.; Loebenberg, D. Pharmacodynamics of a new triazole, posaconazole, in a murine model of disseminated candidiasis. Antimicrob. Agents Chemother. 2004, 48, 137-142. [CrossRef]

211. Howard, S.J.; Lestner, J.M.; Sharp, A.; Gregson, L.; Goodwin, J.; Slater, J.; Majithiya, J.B.; Warn, P.A.; Hope, W.W. Pharmacokinetics and pharmacodynamics of posaconazole for invasive pulmonary aspergillosis: Clinical implications for antifungal therapy. J. Infect. Dis. 2011, 203, 1324-1332. [CrossRef] 
212. Mavridou, E.; Brüggemann, R.J.; Melchers, W.J.; Mouton, J.W.; Verweij, P.E. Efficacy of posaconazole against three clinical Aspergillus fumigatus isolates with mutations in the cyp51A gene. Antimicrob. Agents Chemother. 2010, 54, 860-865. [CrossRef] [PubMed]

213. Sinnollareddy, M.; Peake, S.L.; Roberts, M.S.; Lipman, J.; Roberts, J.A. Using pharmacokinetics and pharmacodynamics to optimise dosing of antifungal agents in critically ill patients: A systematic review. Int. J. Antimicrob. Agents. 2012, 39, 1-10. [CrossRef] [PubMed]

214. Lutsar, I.; Hodges, M.R.; Tomaszewski, K.; Troke, P.F.; Wood, N.D. Safety of voriconazole and dose individualization. Clin. Infect. Dis. 2003, 36, 1087-1088. [CrossRef] [PubMed]

215. Dolton, M.J.; Ray, J.E.; Chen, S.C.A.; Ng, K.; Pont, L.; McLahlan, A.J. Multicenter study of posaconazole therapeutic drug monitoring: Exposure-response relationship and factors affecting concentration. Antimicrob. Agents Chemother. 2012, 56, 5503-5510. [CrossRef] [PubMed]

216. Jang, S.H.; Colangelo, P.M.; Gobburu, J.V.S. Exposure-response of posaconazole used for prophylaxis against invasive fungal infections: Evaluating the need to adjust doses based on drug concentrations in plasma. Clin. Pharmacol. Ther. 2010, 88, 115-119. [CrossRef] [PubMed]

217. Cattaneo, C.; Panzali, A.; Passi, A.; Borlenghi, E.; Lamorgese, C.; Petullà, M.; Re, A.; Caimi, L.; Rossi, G. Serum posaconazole levels during acute myeloid leukaemia induction therapy: Correlations with breakthrough invasive fungal infections. Mycoses 2015, 58, 362-367. [CrossRef] [PubMed]

218. Mitsani, D.; Nguyen, M.H.; Shields, R.K.; Toyoda, Y.; Kwak, E.J.; Silveira, F.P.; Pilewski, J.M.; Crespo, M.M.; Bermudez, C.; Bhama, J.K.; et al. Prospective, observational study of voriconazole therapeutic drug monitoring among lung transplant recipients receiving prophylaxis: Factors impacting levels of and associations between serum troughs, efficacy, and toxicity. Antimicrob. Agents Chemother. 2012, 56, 2371-2377. [CrossRef] [PubMed]

219. Trifilio, S.; Singhal, S.; Williams, S.; Frankfurt, O.; Gordon, L.; Evens, A.; Winter, J.; Talmann, M.; Pi, J.; Mehta, J. Breakthrough fungal infections after allogeneic hematopoietic stem cell transplantation in patients on prophylactic voriconazole. Bone Marrow Transplant. 2007, 40, 451-456. [CrossRef] [PubMed]

220. Chen, Y.C.; Kuo, S.F.; Wang, H.C.; Wu, C.J.; Lin, Y.S.; Li, W.S.; Lee, C.H. Azole resistance in Aspergillus species in Southern Taiwan: An epidemiological surveillance study. Mycoses 2019, 62, 1174-1181. [CrossRef] [PubMed]

221. Tsuchido, Y.; Tanaka, M.; Nakano, S.; Yamamoto, M.; Matsumura, Y.; Nagao, M. Prospective multicenter surveillance of clinically isolated Aspergillus species revealed azole-resistant Aspergillus fumigatus isolates with $\mathrm{TR}_{34} / \mathrm{L} 98 \mathrm{H}$ mutation in the Kyoto and Shiga regions of Japan. Med. Mycol. 2019, 57, 997-1003. [CrossRef]

222. Beer, K.D.; Farnon, E.C.; Jain, S.; Jamerson, C.; Lineberger, S.; Miller, J.; Berkow, E.L.; Lockhart, S.R.; Chiller, T.; Jackson, B.R. Multidrug-resistant Aspergillus fumigatus carrying mutations linked to environmental fungicide exposure-Three States, 2010-2017. MMWR Morb. Mortal. Wkly. Rep. 2018, 67, 1064-1067. [CrossRef]

223. Resendiz Sharpe, A.; Lagrou, K.; Meis, J.F.; Chowdhary, A.; Lockhart, S.R.; Verweij, P.E.; ISHAM/ECMM Aspergillus Resistance Surveillance Working Group. Triazole resistance surveillance in Aspergillus fumigatus. Med. Mycol. 2018, 56 (Suppl. 1), 83-92. [CrossRef]

224. Brauer, V.S.; Rezende, C.P.; Pessoni, A.M.; De Paula, R.G.; Rangappa, K.S.; Nayaka, S.C.; Gupta, V.K.; Almeida, F. Antifungal agents in agriculture: Friends and foes of public health. Biomolecules 2019, 9, 521. [CrossRef] [PubMed]

225. Snelders, E.; Camps, S.M.T.; Karawajczyk, A.; Schaftenaar, G.; Kema, G.H.J.; van der Lee, H.A.; Klaassen, C.H.; Melchers, W.J.G.; Verweij, P.E. Triazole fungicides can induce cross-resistance to medical triazoles in Aspergillus fumigatus. PLoS ONE 2012, 7, e31801. [CrossRef] [PubMed]

226. Di Paolo, M.; Dave, K.; Vijayasingam, A.; Sheth, R.; Luke, E.; Scourfield, A.; Nwankwo, L.; Schelenz, S.; Elborn, J.S.; Armstrong-James, D.; et al. Azoles therapeutic drug monitoring and fungal antimicrobial resistance in adults with cystic fibrosis. Eur. Respir. J. 2018, 52 (Suppl. 62), PA 3409.

227. Seyedmousavi, S.; Meletiadis, J.; Melchers, W.J.; Rijs, A.J.M.M.; Mouton, J.W.; Verweij, P.E. In vitro interaction of voriconazole and anidulafungin against triazole-resistant Aspergillus fumigatus. Antimicrob. Agents Chemother. 2013, 57, 796-803. [CrossRef] [PubMed]

228. Mavridou, E.; Bruggemann, R.J.; Melchers, W.J.; Verweij, P.E.; Mouton, J.W. Impact of cyp51A mutations on the pharmacokinetic and pharmacodynamic properties of voriconazole in a murine model of disseminated aspergillosis. Antimicrob. Agents Chemother. 2010, 54, 4758-4764. [CrossRef] [PubMed]

229. Schauwvlieghe, A.F.A.D.; Buil, J.B.; Verweij, P.E.; Hoek, R.A.S.; Cornelissen, J.J.; Blijlevens, N.M.A.; Henriet, S.S.V.; Rijnders, B.J.A.; Brüggemann, R.J.M. High-dose posaconazole for azole-resistant aspergillosis and other difficult-to-treat mould infections. Mycoses 2020, 63, 122-130. [CrossRef] [PubMed] 
230. Arastehfar, A.; Fang, W.; Pan, W.; Lackner, M.; Liao, W.; Badiee, P.; Zomorodian, K.; Badali, H.; Hagen, F.; Lass-Flörl, C.; et al. YEAST PANEL multiplex PCR for identification of clinically important yeast species: Stepwise diagnostic strategy, useful for developing countries. Diagn. Microbiol. Infect. Dis. 2019, 93, 112-119. [CrossRef]

231. Arastehfar, A.; Daneshnia, F.; Farahyar, S.; Fang, W.; Salimi, M.; Salehi, M.; Hagen, F.; Weihua, P.; Roudbary, M.; Boekhout, T. Incidence and spectrum of yeast species isolated from the oral cavity of Iranian patients suffering from hematological malignancies. J. Oral Microbiol. 2019, 11, 1601061. [CrossRef]

232. Arastehfar, A.; Daneshnia, F.; Kord, M.; Roudbary, M.; Zarrinfar, H.; Fang, W.; Hashemi, S.J.; Najafzadeh, M.J.; Khodavaisy, S.; Pan, W.; et al. Comparison of 21-Plex PCR and API 20C AUX, MALDI-TOF MS, and rDNA sequencing for a wide range of clinically isolated yeast species: Improved identification by combining 21-Plex PCR and API 20C AUX as an alternative strategy for developing countries. Front. Cell. Infect. Microbiol. 2019, 9, 21. [CrossRef]

233. Clinical alert to U.S. Healthcare Facilities: Global Emergence of Invasive Infections Caused by the Multidrug-Resistant Yeast Candida auris. Atlanta: Centers for Disease Control and Prevention; September 2017; Clinical Update. Available online: https://www.cdc.gov/fungal/candida-auris/c-auris-alert-09-17.html (accessed on 21 December 2018).

234. European Centre for Disease Prevention and Control. Candida auris in Healthcare Settings-Europe-First Update 23 April 2018. Stockholm: ECDC. 2018. Available online: https://ecdc.europa.eu/sites/portal/files/ documents/RRA-Candida-auris-European-Union-countries-first-update.pdf (accessed on 23 April 2018).

235. Chowdhary, A.; Sharma, C.; Meis, J.F. Candida auris: A rapidly emerging cause of hospital-acquired multidrug-resistant fungal infections globally. PLoS Pathog. 2017, 13, e1006290. [CrossRef]

236. Aruanno, M.; Glampedakis, E.; Lamoth, F. Echinocandins for the treatment of invasive aspergillosis: From laboratory to bedside. Antimicrob. Agents Chemother. 2019, 63, e00399-19. [CrossRef] [PubMed]

237. Wiederhold, N.P.; Locke, J.B.; Daruwala, P.; Bartizal, K. Rezafungin (CD101) demonstrates potent in vitro activity against Aspergillus, including azole-resistant Aspergillus fumigatus isolates and cryptic species. J. Antimicrob. Chemother. 2018, 73, 3063-3067. [CrossRef]

238. Cornely, O.A.; Hoenigl, M.; Lass-Flörl, C.; Chen, S.C.A.; Kontoyiannis, D.P.; Morrissey, C.O.; Thompson, G.R., 3rd; Mycoses Study Group Education and Research Consortium (MSG-ERC) and the European Confederation of Medical Mycology (ECMM). Defining breakthrough invasive fungal infection-Position paper of the mycoses study group education and research consortium and the European Confederation of Medical Mycology. Mycoses 2019, 62, 716-729. [PubMed]

239. Jenks, J.D.; Mehta, S.R.; Hoenigl, M. Broad spectrum triazoles for invasive mould infections in adults: Which drug and when? Med. Mycol. 2019, 57 (Suppl. 2), S168-S178. [CrossRef]

240. Verweij, P.E.; Chowdhary, A.; Melchers, W.J.; Meis, J.F. Azole resistance in Aspergillus fumigatus: Can we retain the clinical use of mold-active antifungal azoles? Clin. Infect. Dis. 2016, 62, 362-368. [CrossRef] [PubMed]

241. Schauwvlieghe, A.F.A.D.; de Jonge, N.; van Dijk, K.; Verweij, P.E.; Brüggemann, R.J.; Biemond, B.J.; Bart, A.; von dem Borne, P.A.; Verbon, A.; van der Beek, M.T.; et al. The diagnosis and treatment of invasive aspergillosis in Dutch haematology units facing a rapidly increasing prevalence of azole-resistance. A nationwide survey and rationale for the DB-MSG 002 study protocol. Mycoses 2018, 61, 656-664. [CrossRef]

242. Zurl, C.; Waller, M.; Schwameis, F.; Muhr, T.; Bauer, N.; Zollner-Schwetz, I.; Valentin, T.; Meinitzer, A.; Ullrich, E.; Wunsch, S.; et al. Isavuconazole treatment in a mixed patient cohort with invasive fungal infections: Outcome, tolerability and clinical implications of isavuconazole plasma concentrations. J. Fungi 2020, 6, 90. [CrossRef] [PubMed]

243. Jenks, J.D.; Seidel, D.; Cornely, O.A.; Chen, S.; van Hal, S.; Kauffman, C.; Miceli, M.H.; Heinemann, M.; Christner, M.; Jover-Sáenz, A.; et al. Voriconazole plus terbinafine combination antifungal therapy for invasive Lomentospora prolificans infections: Analysis of 41 patients from the FungiScope ${ }^{\circledR}$ registry 2008-2019. Clin. Microbiol. Infect. 2020, 26, 784.e1-784.e5. [CrossRef]

244. Tsitsopoulou, A.; Posso, R.; Vale, L.; Bebb, S.; Johnson, E.; White, P.L. Determination of the prevalence of triazole resistance in environmental Aspergillus fumigatus strains isolated in South Wales, UK. Front. Microbiol. 2018, 9, 1395. [CrossRef]

245. Zoran, T.; Sartori, B.; Sappl, L.; Aigner, M.; Sánchez-Reus, F.; Rezusta, A.; Chowdhary, A.; Taj-Aldeen, S.J.; Arendrup, M.C.; Oliveri, S.; et al. Azole-resistance in Aspergillus terreus and related species: An emerging problem or a rare phenomenon? Front. Microbiol. 2018, 9, 516. [CrossRef]

246. Kupferschmidt, K. New drugs target growing threat of fatal fungi. Science 2019, 366, 407. [CrossRef] [PubMed] 
247. Arastehfar, A.; Carvalho, A.; van de Veerdonk, F.L.; Jenks, J.D.; Koehler, P.; Krause, R.; Cornely, O.A.; Perlin, D.S.; Lass-Flörl, C.; Hoenigl, M. COVID-19 associated pulmonary aspergillosis (CAPA)-From immunology to treatment. J. Fungi 2020, 6, 91. [CrossRef]

248. Siles, S.A.; Srinivasan, A.; Pierce, C.G.; Lopez-Ribot, J.L.; Ramasubramanian, A.K. High-throughput screening of a collection of known pharmacologically active small compounds for identification of Candida albicans biofilm inhibitors. Antimicrob. Agents Chemother. 2013, 57, 3681-3687. [CrossRef] [PubMed]

249. Kim, K.; Zilbermintz, L.; Martchenko, M. Repurposing FDA approved drugs against the human fungal pathogen, Candida albicans. Ann. Clin. Microbiol. Antimicrob. 2015, 14, 32. [CrossRef] [PubMed]

250. Yousfi, H.; Ranque, S.; Cassagne, C.; Rolain, J.M.; Bittar, F. Identification of repositionable drugs with novel antimycotic activity by screening the Prestwick Chemical Library against emerging invasive moulds. J. Glob. Antimicrob. Resist. 2020, 21, 314-317. [CrossRef] [PubMed]

251. Wall, G.; Chaturvedi, A.K.; Wormley, F.L., Jr.; Wiederhold, N.P.; Patterson, H.P.; Patterson, T.F.; Lopez-Ribot, J.L. Screening a repurposing library for inhibitors of multidrug-resistant Candida auris identifies ebselen as a repositionable candidate for antifungal drug development. Antimicrob. Agents Chemother. 2018, 62, e01084-18. [CrossRef] [PubMed]

Publisher's Note: MDPI stays neutral with regard to jurisdictional claims in published maps and institutional affiliations.

(C) 2020 by the authors. Licensee MDPI, Basel, Switzerland. This article is an open access article distributed under the terms and conditions of the Creative Commons Attribution (CC BY) license (http://creativecommons.org/licenses/by/4.0/). 